This document is a personal copy of the accepted version of the paper:

Li, Zaidao, Nathalie Limodin, Amina Tandjaoui, Philippe Quaegebeur, Jean-François Witz, et David Balloy. "Influence of Fe Content on the Damage Mechanism in A319 Aluminum Alloy: Tensile Tests and Digital Image Correlation». Engineering Fracture Mechanics, Modern Imaging Techniques in Fracture and Damage Analyses, 183 (1 octobre 2017): 94-108. https://doi.org/10.1016/j.engfracmech.2017.05.006

The final publication is available at

https://www.sciencedirect.com/science/article/abs/pii/S0013794417300656?via\%3Dihub

\title{
Influence of Fe content on the damage mechanism in A319 aluminum alloy: tensile tests and digital image correlation
}

Zaidao Li a,b,", Nathalie Limodin a, Amina Tandjaoui a , Philippe Quaegebeur a, Jean-François Witz a, David Balloy ${ }^{\mathrm{b}}$

${ }^{a}$ Univ. Lille, CNRS, Centrale Lille, Arts et Métiers Paris Tech, FRE 3723 - LML-Laboratoire de Mécanique de Lille, F-59000 Lille, France

${ }^{b}$ Univ. Lille, CNRS, INRA, ENSCL, UMR 8207 - UMET - Unité Matériaux et Transformations, F-59000 Lille, France

\begin{abstract}
In order to study the role of Fe content on the damage mechanisms of $\mathrm{Al}-\mathrm{Si}-\mathrm{Cu}$ alloy on a microstructural level, a Digital Image Correlation (DIC) method has been developed and performed on two Al-Si-Cu alloys: a high-Fe alloy $(0.1 \mathrm{wt} . \% \mathrm{Fe})$ and a low-Fe alloy (0.8 wt.\% Fe). Tensile tests on flat specimens have been performed, and a Questar long distance microscope has been used for the insitu observation during tensile tests. The field measurements allow to identify and track the development and localization of deformation, and the fracture surfaces of the tensile specimens are analyzed using Scanning Electron Microscopy and Energy-Dispersive X-ray spectrometry (SEM-EDX) to identify the damage mechanisms. The results show that crack initiation occurs through the fracture of hard inclusions, i.e. Si particles, iron-intermetallics and $\mathrm{Al}_{2} \mathrm{Cu}$ particles in the high stress concentration region. Cracks often propagate through the fracture of hard inclusions rather than by their decohesion from the matrix.
\end{abstract}

Keywords: Aluminium alloys; Digital Image Correlation; Experimental strain analysis; Automotive components; Fe content, Damage; Fractography 


\section{Introduction}

The 319 type alloys have received increased interest in the automotive industry in the recent years, and are being widely used in cylinder heads [1]. Due to its application and high demand in the automotive industry, the A319 alloy requires detailed information on the relationship between the microstructures and the mechanical properties.

More than half of all the aluminium currently produced in the EU originates from recycled raw materials due to ecological and economic advantages [2]. The production of recycled aluminium requires $95 \%$ less energy than primary aluminium, and producing aluminium by recycling creates only about $5 \%$ of $\mathrm{CO}_{2}$ quantity produced as by primary production [3]. However, iron, which is present in much higher concentrations in recycled aluminium [2], forms brittle intermetallic inclusions such as $\beta-\mathrm{Al}_{5} \mathrm{FeSi}$ phase. Yi et al. [4] found that, in the absence of other defects such as porosity, the large plate-like $\beta-\mathrm{Al}_{5} \mathrm{FeSi}$ intermetallics in high Fe-content castings of A356 alloy promote crack initiation by raising the stressstrain concentration in the eutectic region. Consequently, effect of $\mathrm{Fe}$ content on the damage mechanisms of the $\mathrm{Al}-\mathrm{Si}-\mathrm{Cu}$ alloy requires more study.

Digital Image Correlation (DIC) has become more common and essential as a measurement method for the deformation analysis [5]. It was first developed by a group of researchers at the University of South Carolina in the 1980s [6]. It is an optical-numerical measurement technique for determining complex displacement and strain fields on the materials surface for static as well as dynamic application [7]. This technique consists in measuring displacement fields between two images of the same specimen at different stages of loading. The displacement field is obtained using the so-called brightness conservation, so that the image of the loaded sample is matched to the reference image [8]. The accuracy and the spatial resolution of the measurement directly depend on the presence of numerous and finely dispersed markers on the specimen surface [9]. Paint is generally used to obtain a surface speckle pattern; however, this random texture could mask the microstructure underneath and thus prevent the study of the relationship between microstructural features and strain heterogeneities. Some interesting application of DIC can be found in Refs [10,11].

In order to study the role of Fe-rich intermetallics on the damage mechanisms of $\mathrm{Al}-\mathrm{Si}-\mathrm{Cu}$ alloy, two Die Cast (DC) alloys which contain different values of Fe/Mn content have been prepared. Then, an experimental protocol has been successfully developed to study the crack initiation and propagation during in-situ tensile tests using DIC. An appropriate colour etching on flat specimen's surface provides a natural pattern suitable for image correlation in order to obtain field measurement at small scales, i.e. at intermetallics or at eutectic Si. 


\section{Experimental procedures}

\subsection{Material and preparation of specimens}

The experimental alloys used in this investigation are two DC AlSi7Cu3 alloys, obtained from PSA Peugeot Citroën, having the chemical compositions shown in Table 1.

Table 1: Chemical compositions of the two experimental AlSi7Cu3 alloys (wt. \%)

\begin{tabular}{|l|l|l|l|l|l|l|l|l|l|l|}
\hline Alloy & $\mathrm{Al}$ & $\mathrm{Si}$ & $\mathrm{Cu}$ & $\mathrm{Fe}$ & $\mathrm{Mn}$ & $\mathrm{Sr}$ & $\mathrm{Mg}$ & $\mathrm{Ti}$ & $\mathrm{Pb}$ & $\mathrm{Zn}$ \\
\hline Low-Fe & bal. & 6.91 & 2.89 & 0.10 & 0.007 & 0.0047 & 0.29 & 0.11 & 0.003 & 0.022 \\
\hline High-Fe & bal. & 7.00 & 3.45 & 0.80 & 0.510 & 0.0100 & 0.28 & 0.12 & 0.05 & 0.24 \\
\hline
\end{tabular}

The specimens used for microstructure characterization and the specimens for in-situ tensile testing were cut out from round bars with a $20 \mathrm{~mm}$ diameter and a $200 \mathrm{~mm}$ length. The $2 \mathrm{D}$ microstructures were examined in the unetched condition using a Nikon YM-EPI light microscope equipped with a Sony colour video camera. The images were processed and analyzed using ImageJ/Fiji software. The parameter used to characterize the size of iron-intermetallics is the Feret diameter, which is defined as the longest distance measured between two parallel tangents on each side of the $2 \mathrm{D}$ object of interest [12].

For the in-situ tensile test specimens, as is shown in Figure 1(a), a shallow hole $(\varnothing=1.5 \mathrm{~mm})$ was drilled in the centre of specimen to have a stress concentration (gross stress concentration factor $\mathrm{K}_{\mathrm{tg}}$, i.e. the ratio of maximum local stress at the edge of the hole and the applied far-field stress remote from the hole, at the edge of the hole is about 3.15 according to [13]) in the chosen Region Of Interest (ROI) that could force the final fracture to occur here. According to Wang et al. [14], the maximum size of pores is more than $1.5 \mathrm{~mm}$ in Lost Foam Cast (LFC) A319 alloy; thus the hole in the present study was chosen so that it can be representative of the large pores in LFC A319.

Besides, after cutting specimens of appropriate size from the original cylindrical bars, a conventional grinding and polishing process was performed on the specimen surface. In order to obtain field measurement at small scales, i.e. at intermetallics or at eutectic $\mathrm{Si}$, an appropriate colour etching was performed on polished flat specimen's surface to provide a natural pattern suitable for image correlation; the protocol is:

- $\quad$ Etchant solution: $100 \mathrm{ml}$ distilled water, $4 \mathrm{~g}$ potassium permanganate and $1 \mathrm{~g}$ sodium hydroxide.

- $\quad$ The etching time is 15 seconds [15]. 
Compared to the conventional random speckle pattern that is usually applied on the specimen surface for use with DIC image analysis, this method does not mask the microstructure underneath, i.e. hard inclusions, and thus we can study the relationship between microstructural features and strain heterogeneities.

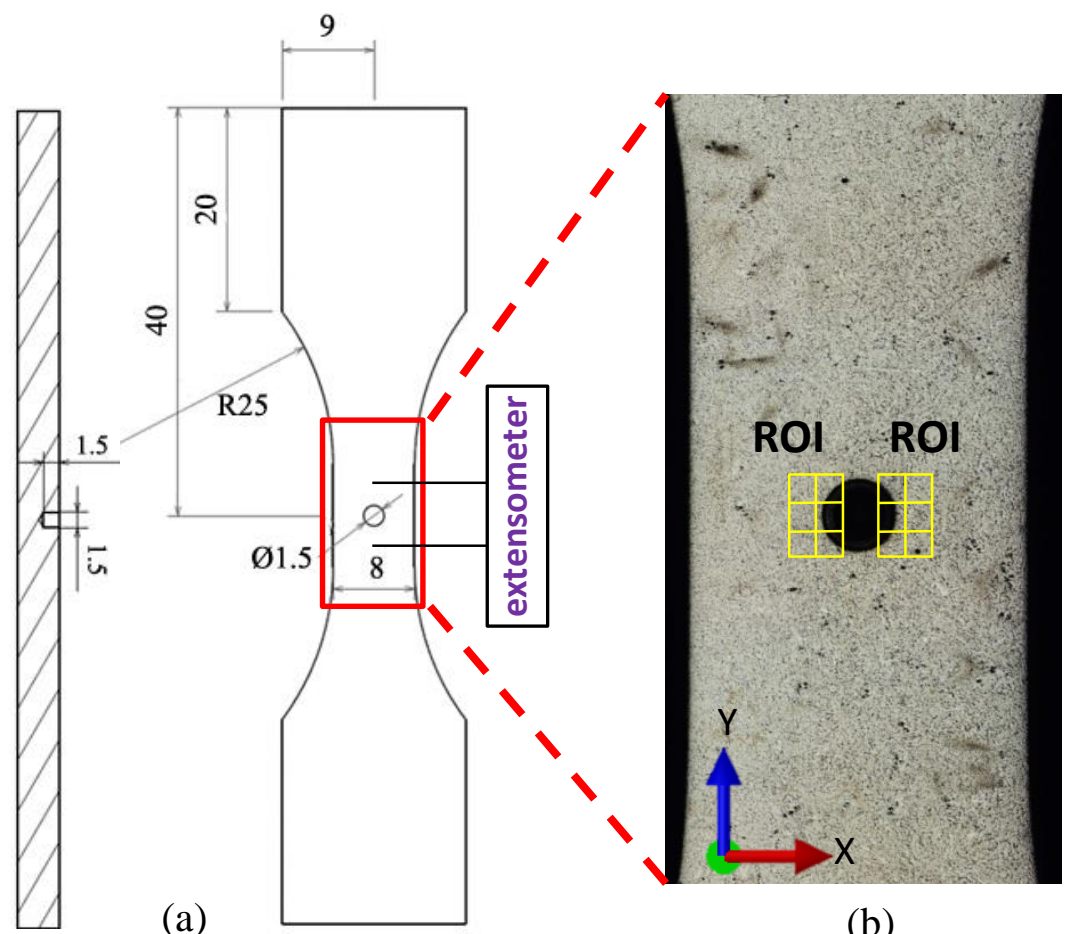

(b)

Figure 1: (a) Schematic drawing of a tensile specimen including dimensions, all sizes are in mm, and (b) photograph of sample showing the hole in the centre of specimen and the Region Of Interest (ROI) for the DIC analysis.

\subsection{Tensile testing}

In-situ 2D tensile tests were performed at a displacement rate of $16 \mu \mathrm{m} / \mathrm{s}$ using an Instron 8501 servohydraulic testing machine. During the tensile test, the applied load was recorded by an extensometer, which was installed across the centre area of the specimen (see Figure 1(a)), to measure the macroscopic deformation. The experimental set-up is illustrated in Figure 2.

In order to record the deformation images during the tensile tests, the test was interrupted at different loading steps. The images were taken using a JAI 500 CCD camera with a resolution of $2048 \times 2048$ pixels and fitted with a long-distance microscope (Questar QM100). The camera was mounted on a translation stage perpendicular to the tensile test set-up. Digital pictures were taken in several adjacent zones of the ROI with a pixel size of about $0.23 / 0.27 \mu \mathrm{m}$ in order to cover the area of interest (see Figure 1). Stitching of the images acquired at each loading step was performed using the plugin MosaicJ in Image $\mathbf{J}$ software [16] which allows rigid registration of images. An appropriate overlap between 
adjacent images is necessary for the further stitching of the images to a larger image which covers the ROI.

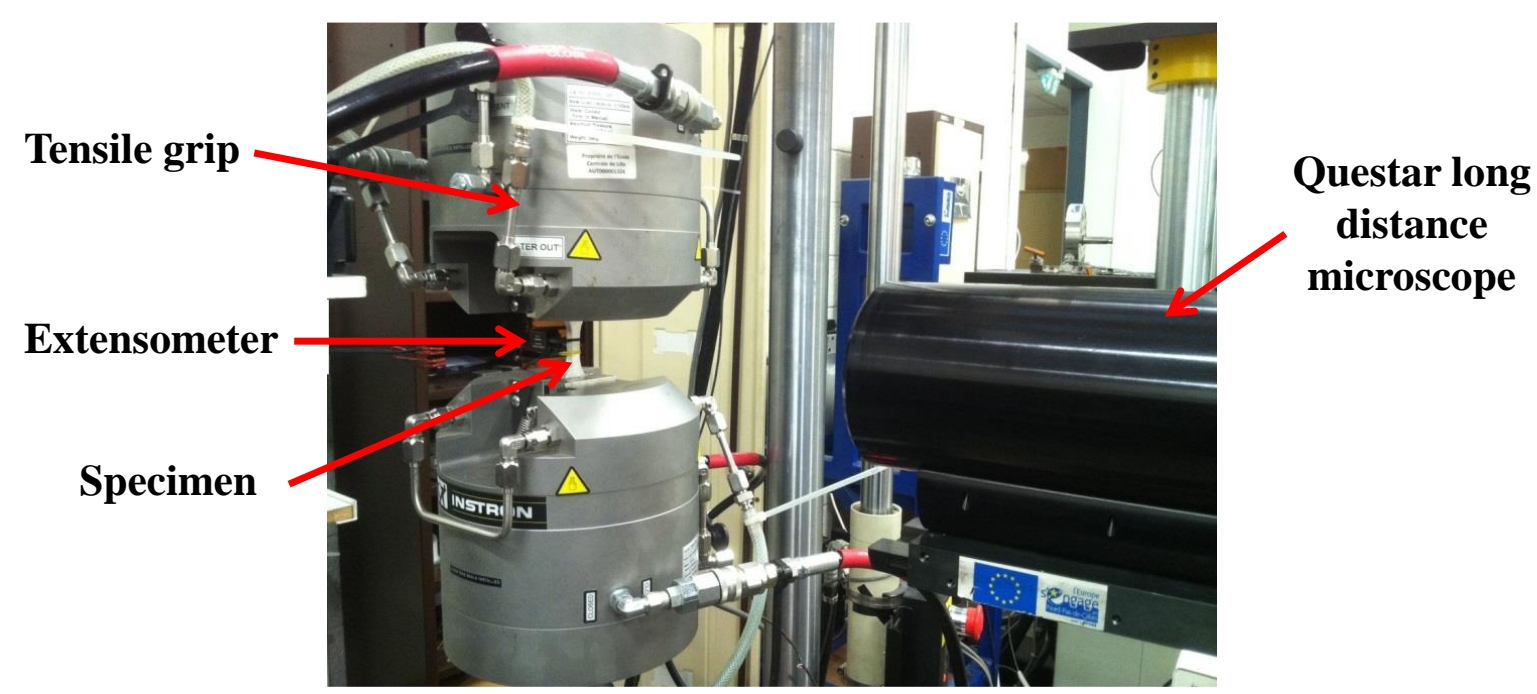

Figure 2: Experimental set-up with Questar microscope.

After the specimens' failure, the fracture surfaces of the specimens have been examined by a JEOL 7800 F LV Scanning Electron Microscope (SEM), and the Energy-Dispersive X-ray spectrometry (EDX) analyses were performed using the OXFORD System Aztec software and an X-Max $80 \mathrm{~mm}^{2}$ premium spectrometer Microanalysis System.

\subsection{Digital Image Correlation (DIC)}

The image analysis method is based on grey value digital images. DIC correlates the grey values of a reference undeformed image with those of a deformed image to determine displacement and strain of the deformed image.

In this study, displacement and strain field measurements were performed with the DIC technique using the YaDICs software developed at LML laboratory (Lille, France) [17]. This platform is based on C++ and has been proven efficient for the correlation of large 3D volumes [1].

As is shown in Figure 3, several steps are necessary in order to identify the transformation: define a metric, choose a sampling and an interpolator, then an optimizer and finally a regularization method.

In the present case, global (rigid and homogeneous) and elastic transformation were chosen in order to compute the Sum of Squared Difference (SSD) metric selected. The metric is evaluated on the whole image, i.e. total image. The gradient descent is retained as the optimizer method. The gradient of the metric is computed regarding the transformation parameters:

$$
\left.\frac{\partial S S D}{\partial \boldsymbol{u}}=\frac{2}{\Omega} \sum_{\boldsymbol{x} \in \Omega}(f(x)-g(\boldsymbol{x}+\boldsymbol{u}(\boldsymbol{x}))) \frac{\partial g(\boldsymbol{x}+\boldsymbol{u}(\boldsymbol{x}))}{\partial \boldsymbol{u}}\right)(1)
$$


where $\mathrm{f}(\mathrm{x})$ and $\mathrm{g}(\mathrm{x})$ are the grayscale values of the deformed and the reference images, $\Omega$ denotes the integration area, $\mathrm{x}$ is the vector denoting the position of any pixel/voxel, $\mathrm{u}$ is the displacement vector for each position $\mathrm{x}$.

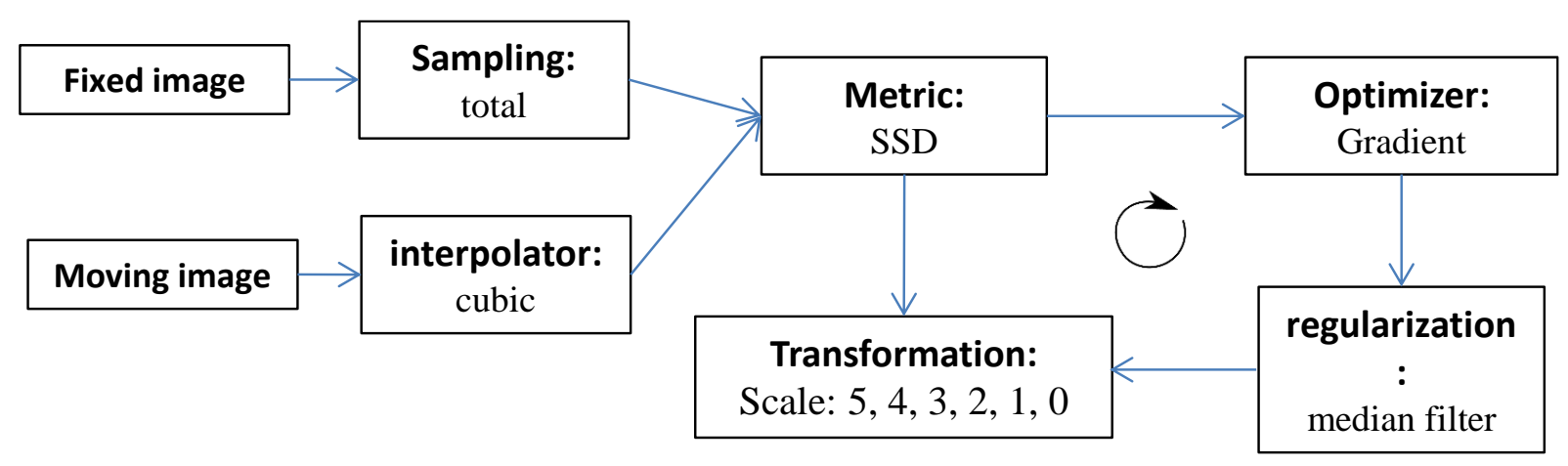

Figure 3: The basic registration components of YaDICs [17] image correlation platform at LML.

Finally, a bi-cubic interpolator is employed to apply the transformation to the moving image at each iteration. The correlation is based on a multiscale resolution strategy like a pyramid scheme. At each scale, the transformation may be different: homogeneous deformations are looked for at the coarsest scales while, local deformations at finer scales are searched for at the nodes of a FE-like grid whose spacing gets finer and finer until the last scale is reached, i.e. the full resolution image. In this work, six scales are used, the coarsest one is "scale 5" where one "macro" voxel is averaged over $2^{5} \times 2^{5}$ pixels, while the full resolution image corresponds to "scale 0" [1].

For the 2D DIC analysis, the correlation calculation is a sequence of Optical Flow Integrated (OFI) and Optical Flow Finite Element methods (OFFEM). The analysis sequence “OFI_H, OFI_H, OFI_H, OFFEM, OFFEM, OFFEM" is used for scales 5 to 0 :

- OFI_H is defined by the OFI method, and assumes a homogeneous deformation such as rigid body motions, i.e. translations and rotations, and global strains. It measures the similarity by using Sum of Squared Differences (SSD).

- OFFEM is the Optical Flow elastic transformation based on Finite Element Methods; it is used for the elastic deformation, as it has a good spatial coherence.

The detailed parameters used in this work are shown in Table 2.

In the present work, the uncertainty of the measured displacement field was calculated to assess the feasibility of DIC. Uncertainty of DIC is estimated from the standard deviation of the displacement field measured between two images, i.e. one at a reference position and another one after a small translation [8]. Here the specimen was placed on a translation stage and, after acquisition of a reference image, the specimen was shifted by approximately $10 \mu \mathrm{m}$ in a direction perpendicular to the optical axis of the Questar microscope. 
Table 2: The parameters for DIC analysis using YaDICs

\begin{tabular}{|l|l|l|}
\hline Specimen name & Low Fe & High Fe \\
\hline Pixel/voxel size $(\mu \mathrm{m})$ & 0.27 & 0.23 \\
\hline Element size $($ pixels $)$ & $32 \times 32$ & $500 \times 300$ \\
\hline Measured field $(\mu \mathrm{m})$ & $500 \times 500$ & \multicolumn{2}{|l|}{} \\
\hline Analysis sequence & $\begin{array}{l}\text { Scale: } 5,4,3,2,1,0 \\
\text { OFI_H, OFI_H, OFI_H, OFFEM16, OFFEM16, OFFEM16 }\end{array}$ \\
\hline
\end{tabular}

\section{Results}

\subsection{Microstructure analysis}

The typical microstructure of a low-Fe DC A319 alloy is presented in Figure 4(a): Al-matrix, $\mathrm{Al}_{2} \mathrm{Cu}$ phases and eutectic Si-particles are the major features. The microstructure inherited from casting at a high cooling rate $\left(30^{\circ} \mathrm{C} / \mathrm{s}\right)$ is fine with an average Secondary Dendrite Arm Spacing (SDAS) of about $20 \mu \mathrm{m}$.

Quantitative analysis shows that the surface fraction of $\mathrm{Al}_{2} \mathrm{Cu}$ phase and eutectic $\mathrm{Si}$ are $1.2 \%$ and $7 \%$, respectively. In addition, most of eutectic Si particles, which have a size between 1 and $12 \mu \mathrm{m}$, are well distributed in the alloy.
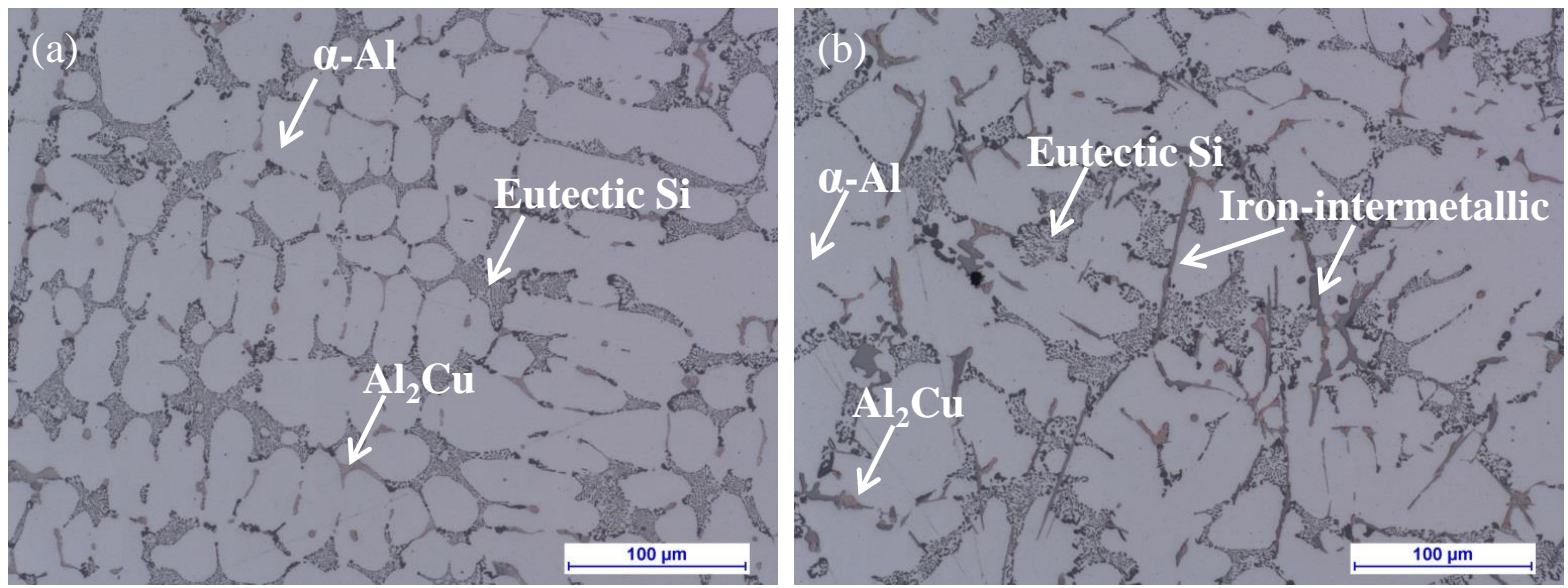

Figure 4: Optical microstructure of (a) low Fe sample and (b) high Fe sample.

For the high-Fe alloy, as is shown in Figure 4(b), iron-rich intermetallics (mainly $\beta-\mathrm{Al}_{5} \mathrm{FeSi}$ phase) were observed in specimen, and their amount and size were proportional to the Fe content. However, the SDAS, the size of eutectic $\mathrm{Si}$ and that of $\mathrm{Al}_{2} \mathrm{Cu}$ phase mainly depend on the solidification time, and do not show a clear correlation with the Fe content. 
The influence of the Fe content on distributions of iron-intermetallics as functions of Feret diameter can be observed in Figure 5. The average size of iron-intermetallics increases with the Fe content increase, and the maximum length of iron-intermetallic compounds increases from $20 \mu \mathrm{m}$ to $63 \mu \mathrm{m}$ when the $\mathrm{Fe}$ content increases from $0.1 \%$ (low-Fe) to $0.8 \%$ (high-Fe), respectively. In addition, the surface area fraction of the iron-intermetallics also increases from $0.14 \%$ in low-Fe alloy to $2.48 \%$ in high-Fe alloy.

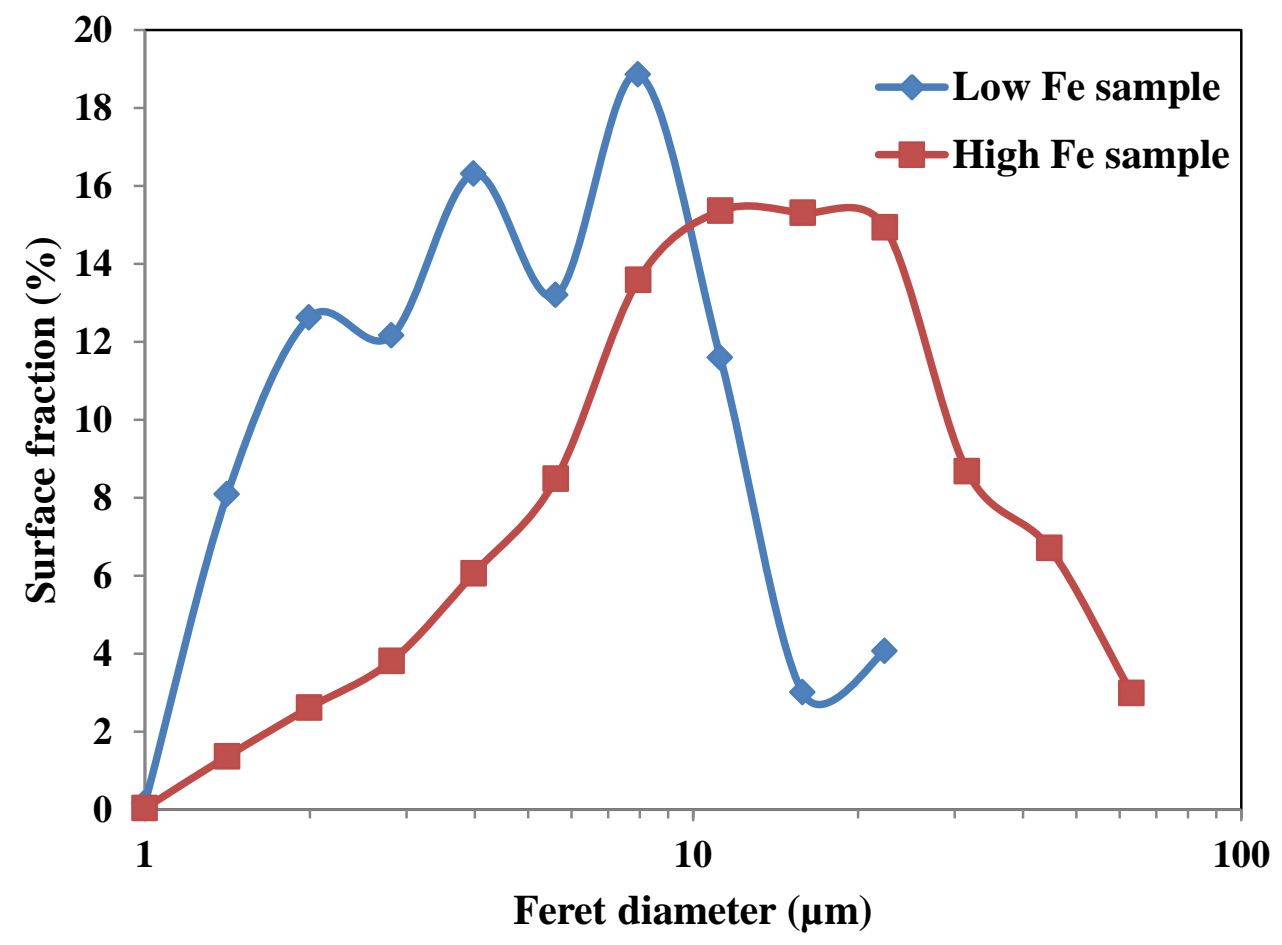

Figure 5: Distributions of iron-intermetallics as functions of Feret diameter in low Fe alloy (blue curve) and high Fe alloy (red curve).

\subsection{DIC analysis}

\subsubsection{Measurement uncertainty}

Figure 6 shows the metallographic image of the studied alloy before and after color etching, and the corresponding grey-level distributions in the same area of the specimen surface. Before etching, the histogram shows one tall peak for the aluminium matrix and other very small peaks (see arrows in Figure 6(a)) for pores, eutectic Si particles and intermetallics. After etching (see Figure 6(b)), the image shows a wider range of grey-levels within the aluminium matrix where etching has revealed segregation and precipitates [18]. The large standard deviation of the grey-level distribution of the etched specimen surface shows a richer speckle pattern which is expected to be sufficient to use DIC technique on the microstructural scale. 

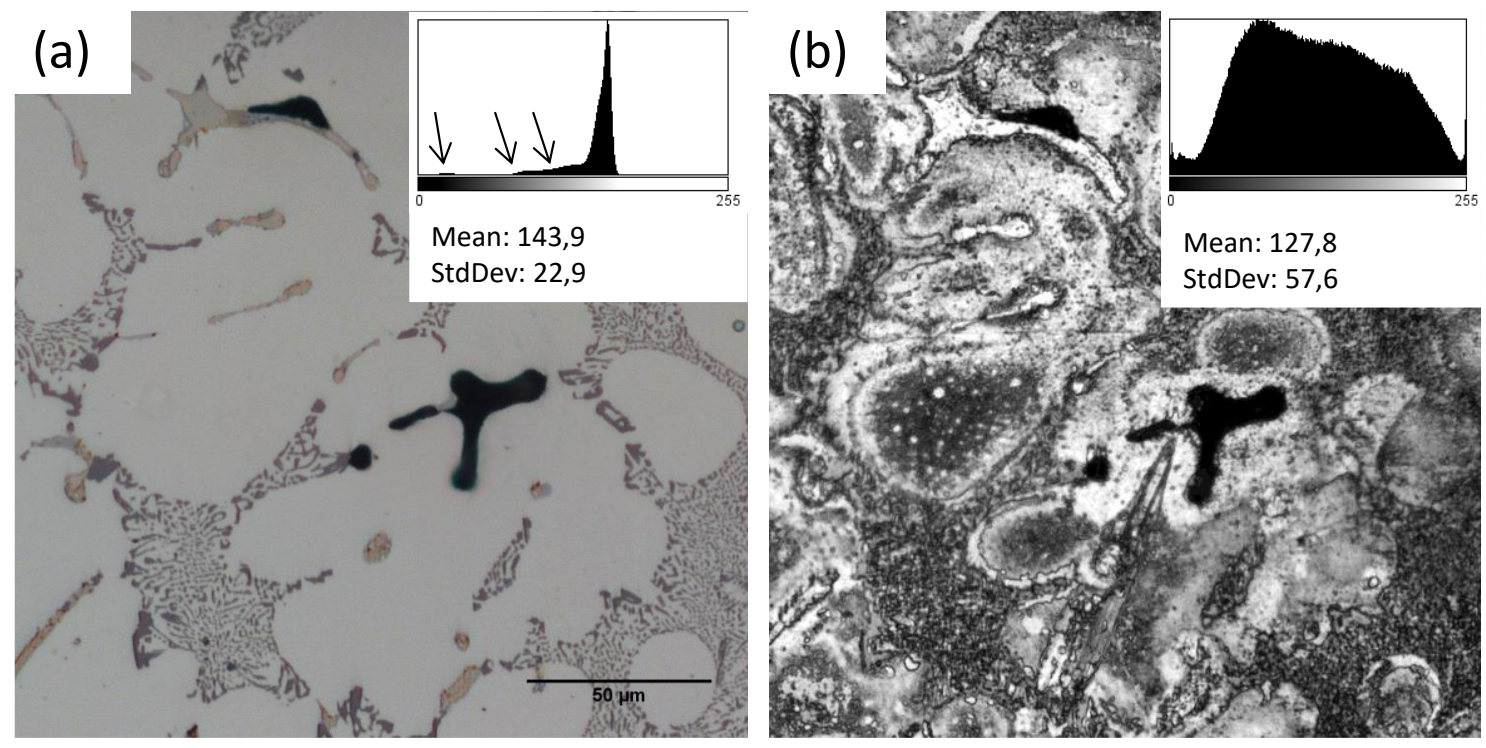

Figure 6: Optical microscopy images of the specimen surface (a) before and (b) after etching

As is shown in Figure 7, the uncertainty ranges from 0.036 to $0.003 \mu \mathrm{m}$ ( 0.13 to 0.01 pixels) for sizes of element between 4.32 to $34.56 \mu \mathrm{m}$ (16 to 128 pixels). It indicates that the uncertainly strongly depends on the size of element, one observes that a rapid decrease of the uncertainty is obtained when the element size increases. The surface texture obtained by etching is proved sufficient to use the DIC technique on the microstructural scale with a good image correlation quality [8]. The element size used in this work, i.e. $8.64 \mu \mathrm{m}$ (32 pixels), can be considered good enough to yield an uncertainty that remains low, i.e. $0.021 \mu \mathrm{m}$ ( 0.08 pixels), in the measured field.

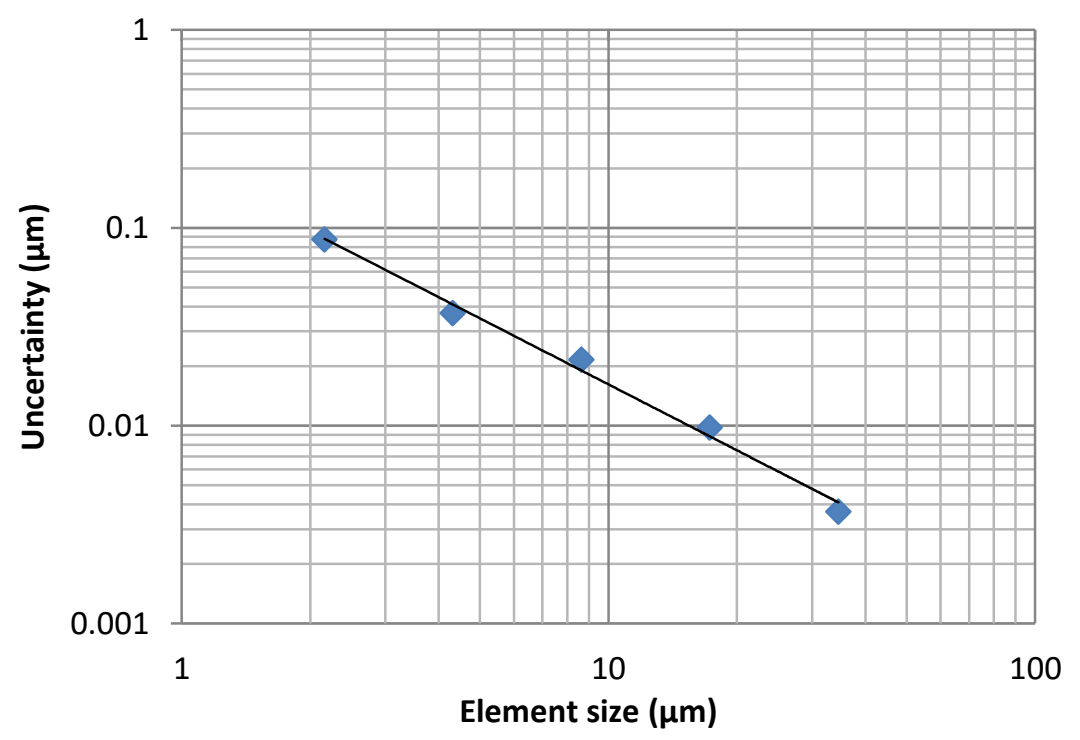

Figure 7: Uncertainty of the measured displacement field. 


\subsubsection{Field measurements in low-Fe specimen}

In both alloys (low and high Fe content), the specimen failed from a crack inside the ROI. Figure 8 represents the representative conventional stress-strain curves for the two studied alloys. Tensile test specimens were machined according to ISO 6892-1 (ISO 2009) and, for each alloy, three tensile tests were carried out [19]. During the in-situ tensile tests, the strains, called global strain $\varepsilon$ hereafter, were measured by extensometer, whose location can be seen in Figure 1, in each loading step and these global strain values were used to draw the in-situ tensile curves (blue points in Figure 8).
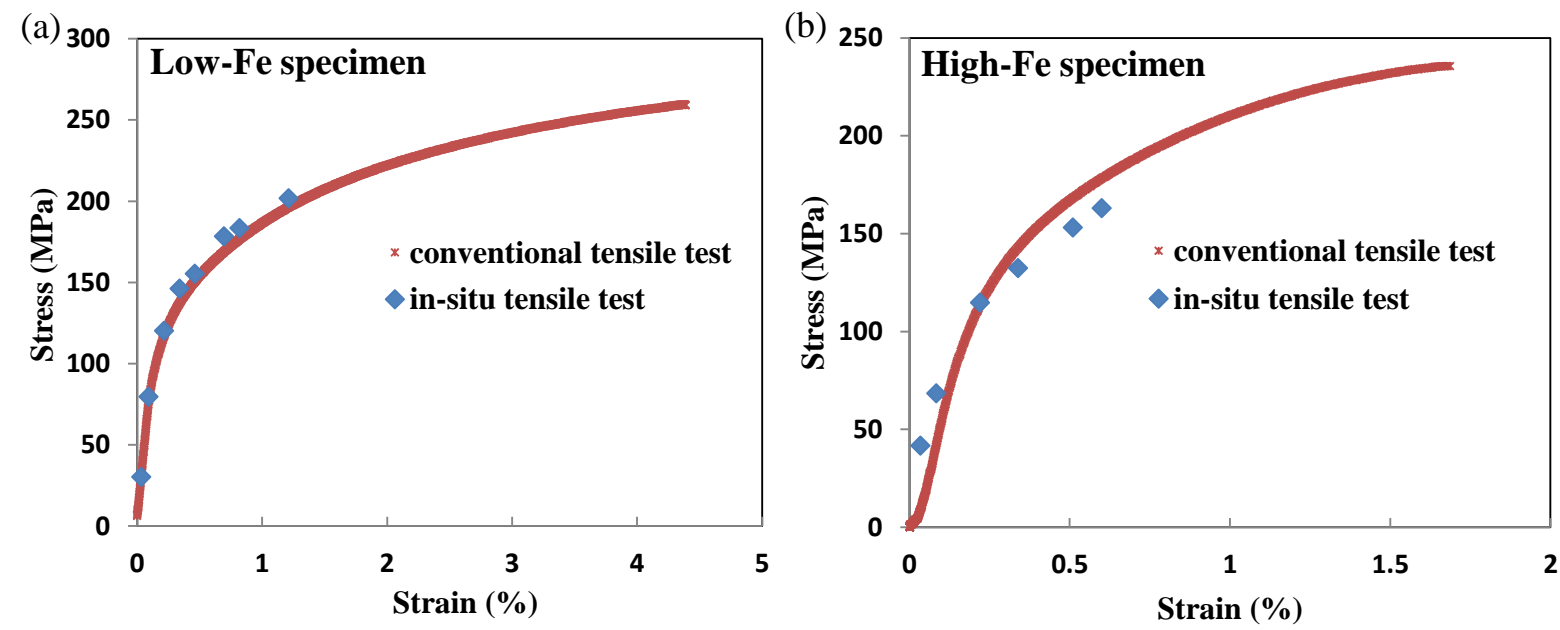

Figure 8: Stress-strain curves for the (a) low-Fe specimen and (b) high-Fe specimen.

As is shown in Figure 8(a), the low-Fe specimen failed at a nominal gross stress of $202 \mathrm{MPa}$ and overall average strain of $1.29 \%$. The high-Fe specimen failed at a nominal gross stress of $159 \mathrm{MPa}$ and an overall average or global strain $\varepsilon$ of $0.61 \%$ (Figure $8(b)$ ).

Compared to the results of conventional tensile test for the same alloys (i.e. $\varepsilon=3.8 \pm 0.3 \%$ for low-Fe specimen and $\varepsilon=1.3 \pm 0.1 \%$ for high-Fe specimen), the elongations of the two specimens for in-situ tensile tests presented here are lower, and this can be attributed to the artificial hole in the centre of specimen. In addition, the large stress concentration also explains why the crack forms near the edge of the hole.

Displacement and strain fields for the two specimens (i.e. low-Fe and high-Fe) are shown and compared at different loading levels (before the final fracture) in the area where a crack was observed during the test, i.e. at the hole edge. This area is called 'analysis area' hereafter.

For the low-Fe specimen, displacement and strain fields obtained by DIC at different loading steps are illustrated in Figure 9. The Optical Microscopy (OM) image of analysis area (obtained before the test) has been registered to the reference Questar image (obtained without any applied load) and superposed to the measured fields to allow comparison of the strain localization and microstructure. 

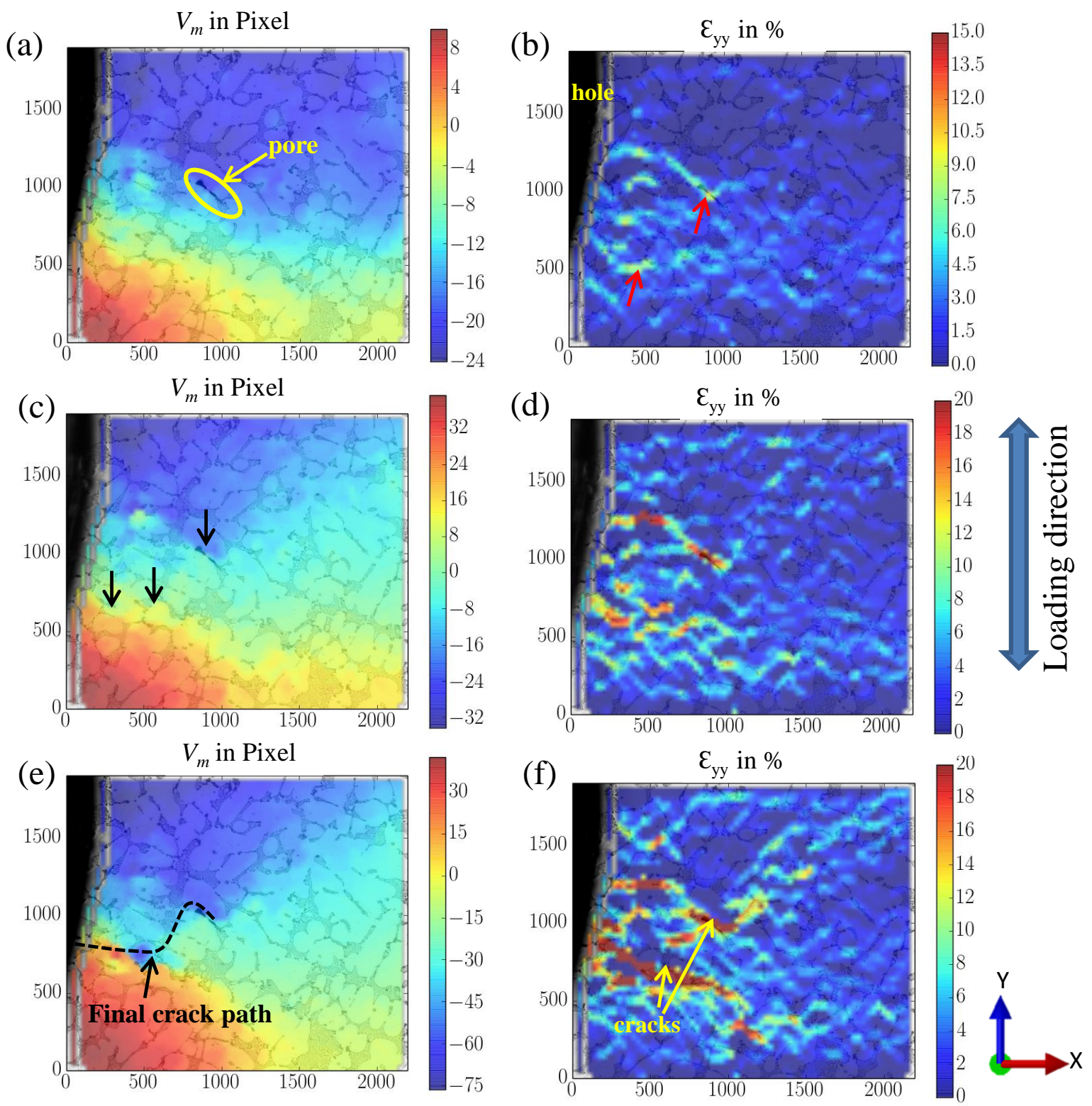

Figure 9: $(a, c, e)$ Displacement and $(b, d, f)$ strain fields (in pixels, 1pixel $=0.22 \mu m$ ) in the analysis area along the loading direction at global strain $(a, b) \varepsilon=0.56 \%,(c, d) \varepsilon=0.88 \%$ and $(e, f) \varepsilon=1.06 \%$ for low-Fe specimen. Loading was along the vertical direction and OM images of the microstructure in the unloaded state are superimposed, displacement Vm is along y-axis.

Indeed, although the crack is not visible at the low strain level, i.e. at $0.56 \%$, slight strain localizations are already observed (see arrows in Figure 9(b)), and they increase as the load is increasing. The strain field within the analysis area shows some strain localization at hard inclusions and pores when the global strain is $0.88 \%$ (Figure 9(d)), which correspond to the displacement discontinuities in Figure 9(c) (see black arrows). The presence of a displacement discontinuity means that there is a crack already nucleated at a strain of $0.88 \%$. This also indicates a good correlation between crack location and strain localization at the beginning of the test. The discontinuities in displacement fields along the loading direction have become more obvious at a strain of $1.06 \%$ (Figure 9(e)). A good correlation is observed between strain localizations and cracks (Figure 9(f)). 
A comparison between the OM image in analysis area and the corresponding Questar image at the strain of $1.06 \%$ for low-Fe specimen is shown in Figure 10. Due to the low quality of image, no obvious crack can be observed in the Questar image at the strain of $0.88 \%$. When the load increases, the main crack becomes visible at the strain of $1.06 \%$ (as is shown in Figure 9(b)), and corresponds to a large local strain deformation (Figure 9(f)). Then the crack is observed to grow quickly with a further increase of loading. In addition, comparison of Figure 10(a) with Figure 10(b) shows that some eutectic Si particles and a surface pore were involved in the crack path.
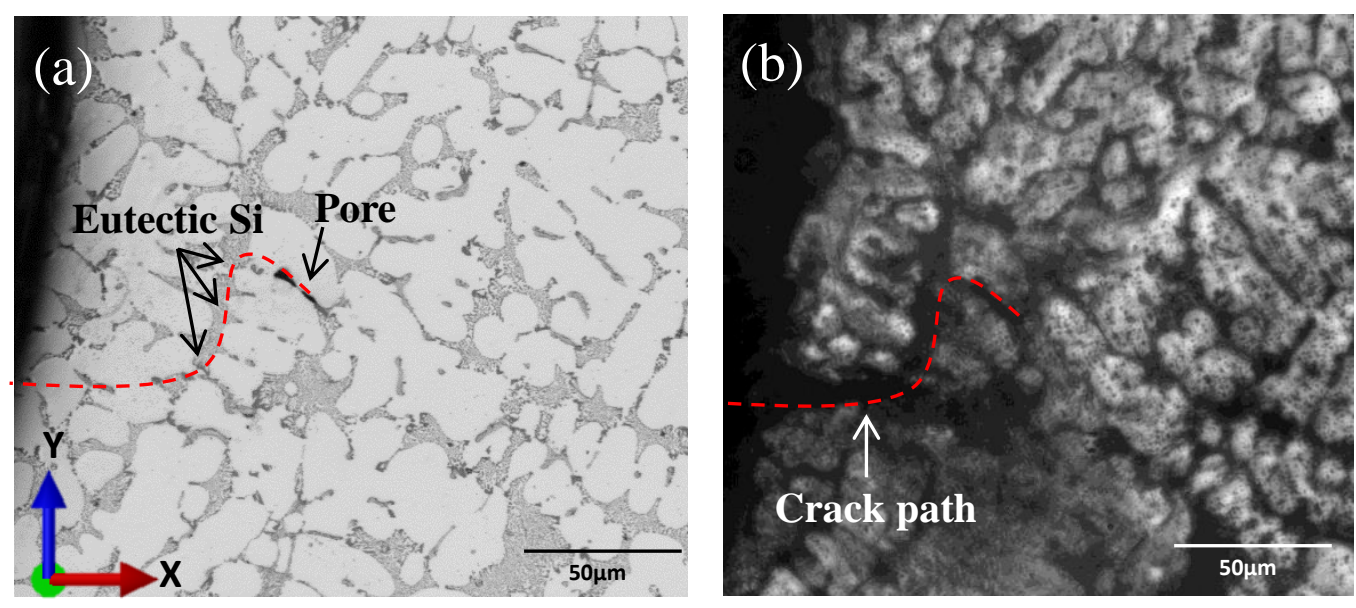

Figure 10: (a) OM image of analysis area before the tensile test, and (b) the corresponding Questar image at the strain $\varepsilon=1.06 \%$ for low-Fe specimen.

Due to the low quality of Questar images, cracks detected from the Questar image are faint, and it is difficult to distinguish to which microstructural constituent the cracks do correspond. Therefore, the fracture surface of specimen was observed by SEM, and the details are discussed in the following section of the present paper.

\subsubsection{Field measurements in High-Fe specimen}

Figure 11 shows the displacement and strain fields measured in the analysis area at different loading steps for the tensile test of the high-Fe specimen. Figure 12 shows the comparison between the OM image in analysis area and the corresponding Questar image at the strain of $0.51 \%$ for high-Fe specimen. One can notice that, in order to show the experimental fields in high magnification, a small region which contains the crack initiation and propagation has been chosen and extracted from the large examined ROI.

No obvious cracks are observed in the Questar images when the global strain is $0.21 \%$ and $0.33 \%$. However, as can be seen in Figure 11(b) and (d), strain localizations are observed to increase at increasing load in these two steps in the neighbourhood of the hole which introduces high stress concentration. Visible crack (Figure 12(b)) is observed from the Questar image at a global strain of 
$0.51 \%$, which corresponds to an obvious displacement discontinuity, then the cracks propagate until final fracture with further loading increase.

The comparison of the OM image of analysis area (Figure 12(a)) and the cracks which are observed from the corresponding Questar image (Figure 12(b)) shows that the cracks are more prone to occur along the iron-intermetallics.

(a)

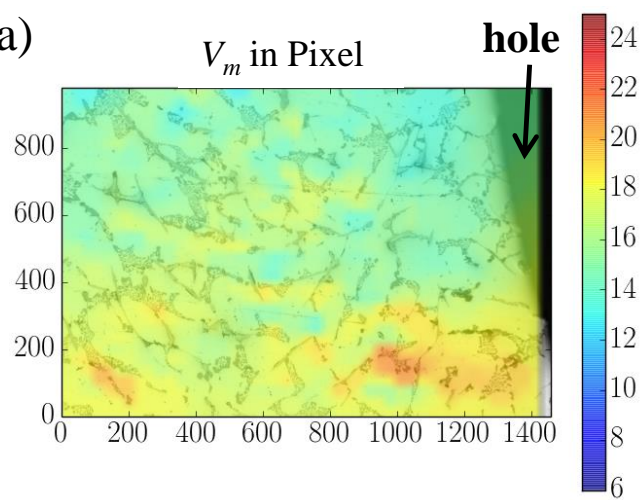

(c)

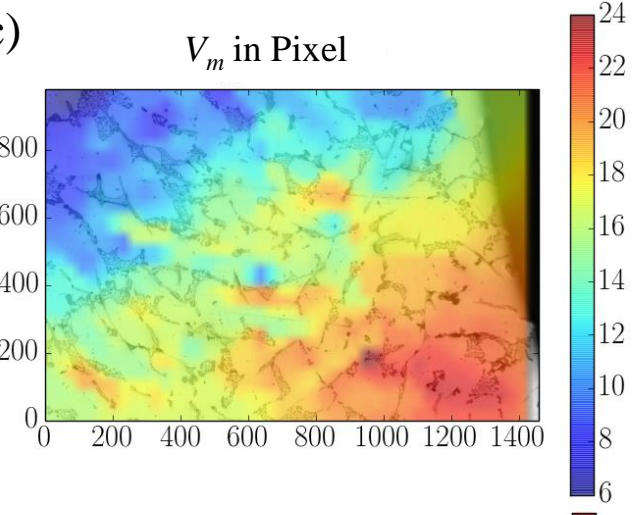

(e)

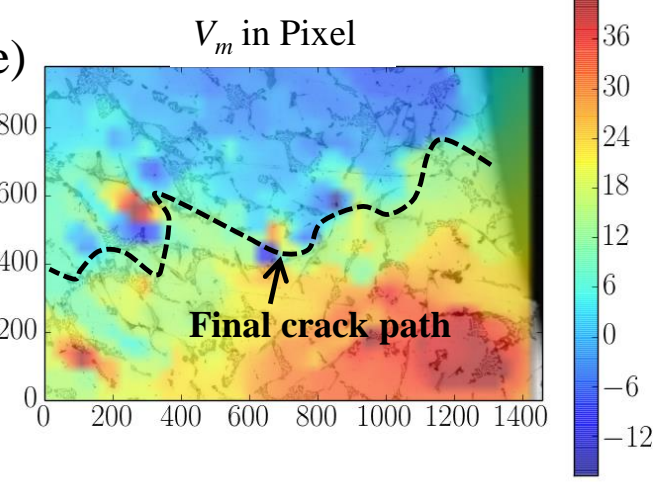

(b)

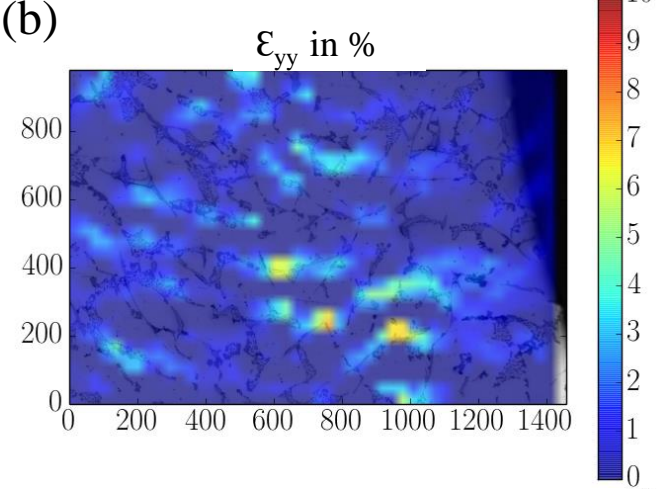

(d)
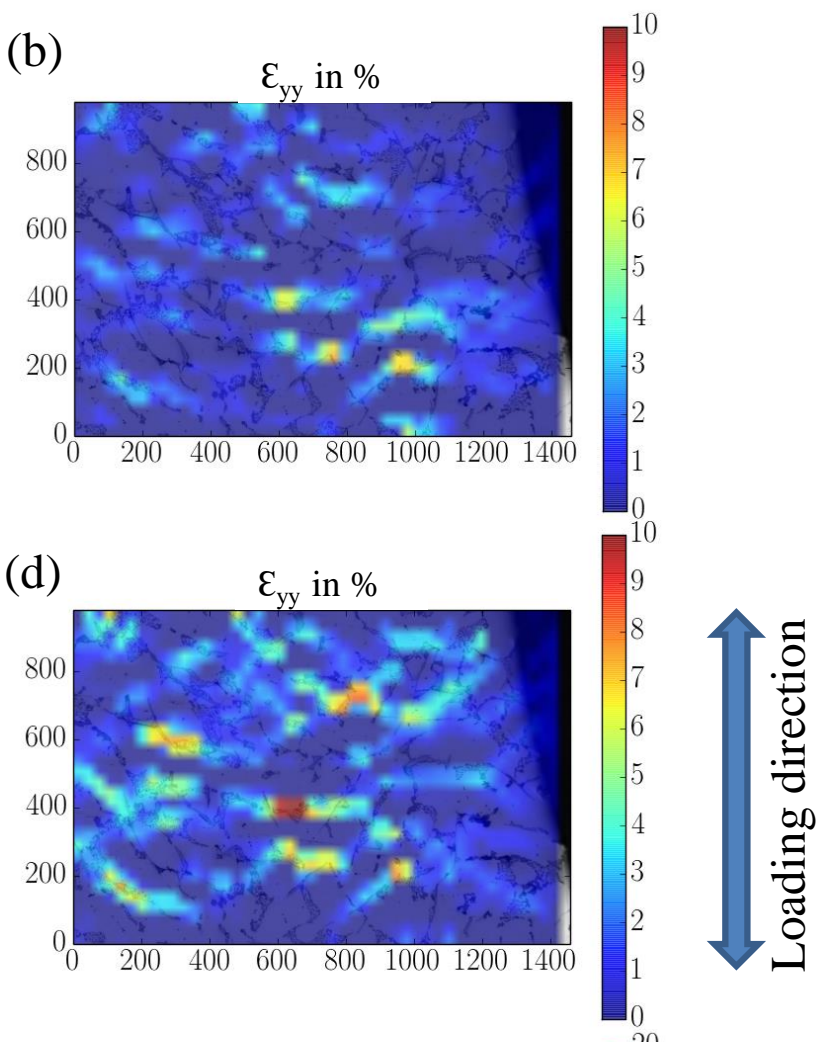

(f)

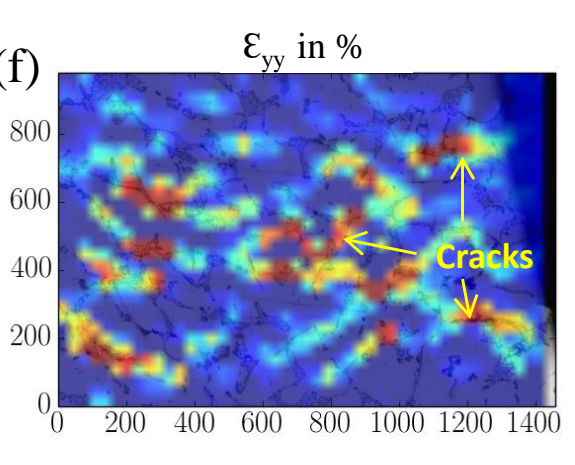

列

Figure 11: $(a, c, e)$ Displacement field and $(b, d, f)$ strain field (in pixels, 1pixel $=0.22 \mu m$ ) in the analysis area along the loading direction at global strain $(a, b) \varepsilon=0.21 \%,(c, d) \varepsilon=0.33 \%$ and $(e, f)$ $\varepsilon=0.51 \%$ for high-Fe specimen. Loading was along the vertical direction and OM images of the microstructure in the unloaded state are superimposed, displacement Vm is along y-axis. 

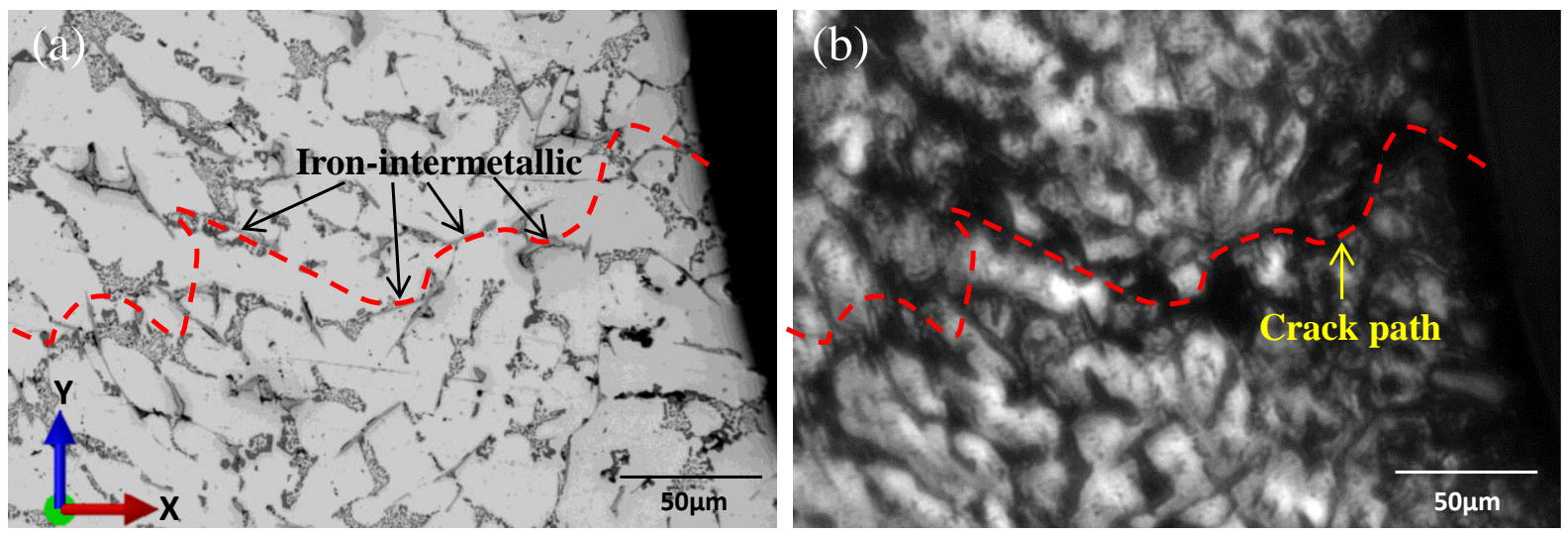

Figure 12: (a) OM image of analysis area before the tensile test, and (b) the corresponding Questar image at the strain $\mathcal{E}=0.51 \%$ for high-Fe specimen.

\subsubsection{Fracture surface analysis in low-Fe specimen}

The OM images of the microstructure in the unloaded state have been systematically superimposed to the DIC fields to check the correspondence between strain localization and microstructure. However, cracks are not clearly visible in the Questar image, especially for the microcracks. Thus, in order to better understand the influence of microstructural constituents on strain heterogeneities, the specimen's surface after failure has been observed with Scanning Electron Microscope (SEM) to allow direct comparison of the microcracks observed at a higher resolution. In addition, 2D observations cannot follow cracks in final fast fracture areas. Thus, in order to get more details about the crack propagation and final fracture in the alloys, Backscattered Secondary Electron (BSE) microscopy has been used to examine the final fracture surfaces.

As is seen in Figure 13(a), cracks paths are observed clearly in the BSE images of low-Fe specimen, and micro-cracking occurs mainly in the $\mathrm{Al}_{2} \mathrm{Cu}$ phase (pointed out by yellow arrows), which is distributed along the crack path. This result proves the role of $\mathrm{Al}_{2} \mathrm{Cu}$ phase on the crack propagation during loading and that the final fracture is prone to occur along the $\mathrm{Al}_{2} \mathrm{Cu}$ phase.

In Figure 13(c), strain heterogeneity is observed in the selected area of the specimen (highlighted with a frame in Figure 13(a)) at the step before the crack is visible in the Questar image (see Figure 12(b)); strain localization appears in the hard inclusions (eutectic $\mathrm{Al}-\mathrm{Si}, \mathrm{Al}_{2} \mathrm{Cu}$ ) and pores at a stress level of $184 \mathrm{MPa}$ (average strain of about $0.88 \%$ ). The comparison between Figure 13(b) and Figure 13(c) proves that the zones with large deformation are correlated to final fracture or microcracks. 


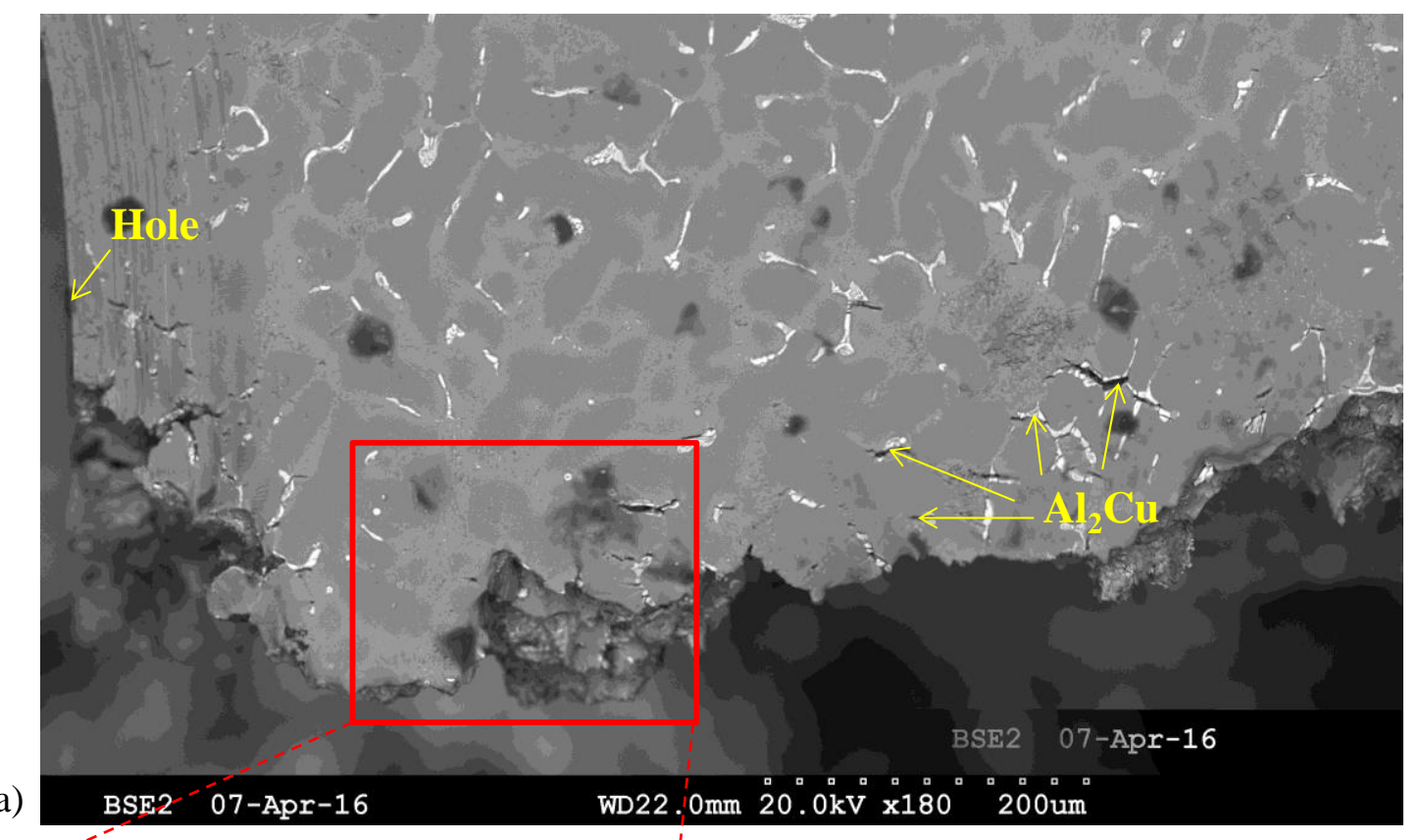

(a)
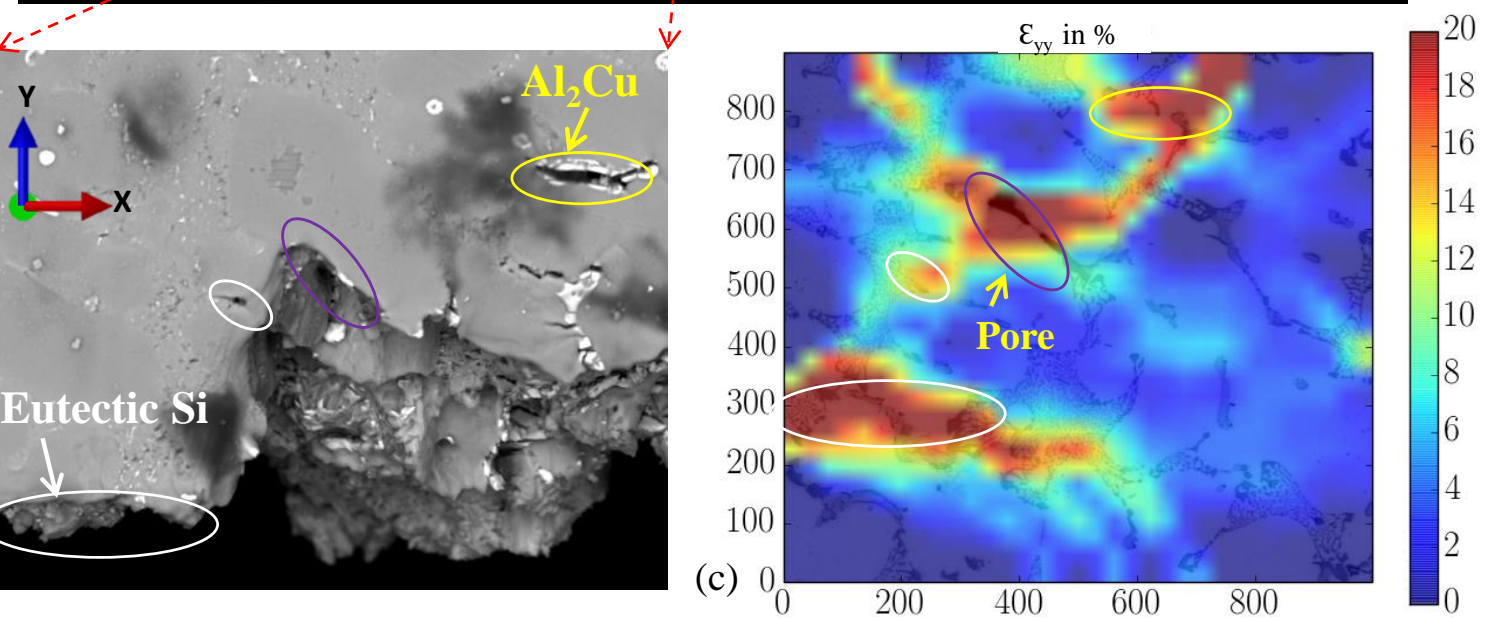

Figure 13: SEM image of polished flat surfaces of the specimen after tension test (a) overall view, $(b)$ magnified view as enclosed by box in (a), and (c) the corresponding strain field ( $(\varepsilon=0.88 \%)$ computed from DIC.

In addition, as is shown in Figure 14, fracture analysis using SEM-EDX has been performed on the fracture surface. Figure 14(e) shows a general view of the fracture surface; the analysis area (marked by red box) is located below the hole where cracks initiate and propagate. BSE images of both sides of the fracture surface for low-Fe specimen are placed side by side (Figure 14(a) and (b)). The corresponding X-ray elemental mappings of the fracture surface for the specimen are shown in Figure 14(c) and (d). The comparison of both fracture surfaces allows to determine whether a hard inclusion has failed by fracture (in this case it should be found in both sides of the fracture surface), or by debonding (in which case it should remain attached to one side only).

The eutectic Si particles, $\mathrm{Al}_{2} \mathrm{Cu}$ particles and iron-intermetallics are observed in the fracture surface. Figure 14(c) and (d) reveal that hard inclusions, i.e. $\mathrm{Al}_{2} \mathrm{Cu}$ phase and $\mathrm{Si}$ particles, occupy a large area fraction of the fracture surface for low-Fe specimen. 
In addition, as can be observed seen in Figure 14(c) and (d), both fracture (white solid arrows) and debonding (white dotted arrows) of these hard inclusions are found in the fracture surface. The observations reveal that more fracture than decohesion is found in all fracture surfaces.
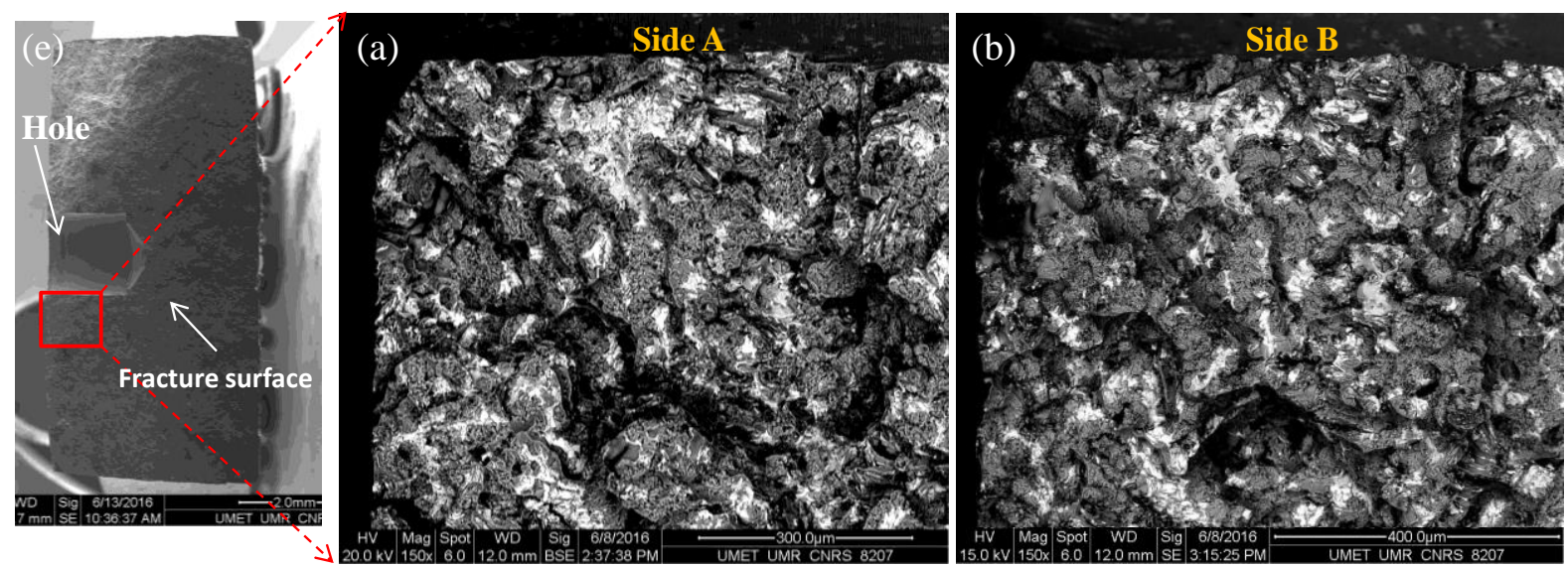

Fe-intermetallics

$\mathrm{Al}_{2} \mathrm{Cu}$

Eutectic Si
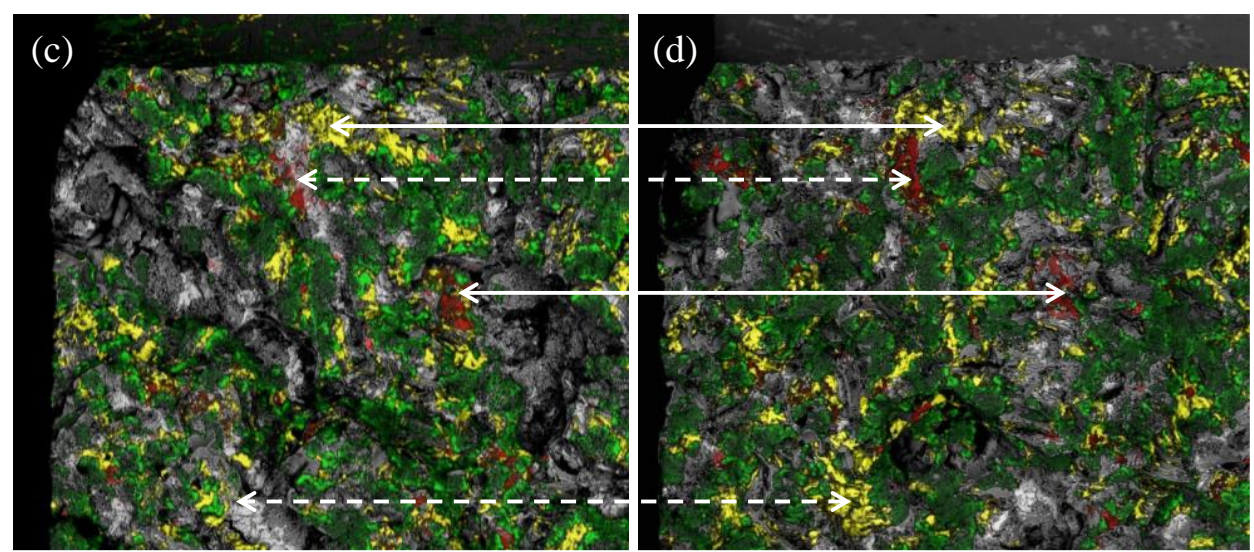

Figure 14: (a), (b) BSE images of the fracture surface of low-Fe specimen and (c), (d) corresponding $X$-ray mapping images showing the distribution of hard inclusions (eutectic Si, iron-intermetallics, Al2Cu phases), (e) SE image of the fracture surface of low-Fe specimen showing the analysis area.

\subsubsection{Fracture surface analysis in high-Fe specimen}

In order to distinguish the phases along the crack path precisely, the strain field (Figure 15(a)) in the analysis area is compared with that in the same area of BSE image (Figure 15(b)). In both images, the crack path is marked by a dotted line. Figure 15 shows that crack goes through hard inclusions and that this crack is prone to go through iron-intermetallics (marked by arrows in Figure 15(b)). As can be noticed from Figure 15, most of the strain localization can be ascribed to hard inclusions, especially iron-intermetallics.

One can notice a high strain localization in an area (circled in white in Figure 15(a)) where no crack can be observed from the corresponding zone in BSE image; this may be due to a subsurface pore located below the specimen surface so that, although the deformation exists, the crack cannot be detected from 2D observation. 


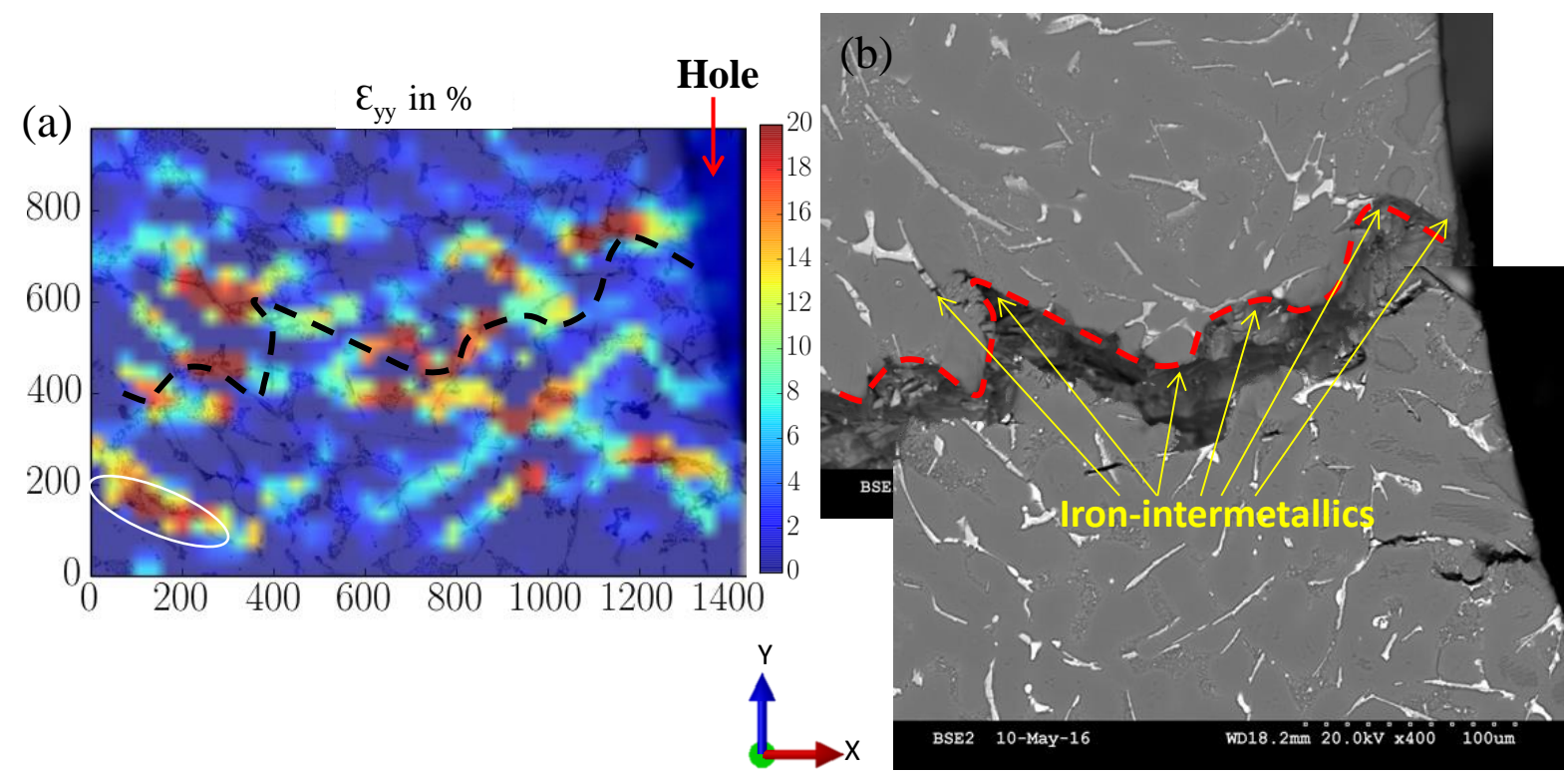

Figure 15: (a) Strain field ( $(\mathcal{E}=0.51 \%)$ computed from DIC in analysis area of high-Fe specimen, and (b) the corresponding BSE image of the flat fracture surface.

Figure 16(a) and (b) show the BSE images of two fracture surfaces close to the hole in high-Fe specimen. The analysis of fracture surfaces reveals considerably different characteristics for high-Fe specimen as compared to low-Fe specimen. A larger area of iron-intermetallics (red area) is observed, which proves the role of iron-intermetallics on the crack propagation and final fracture.

Figure 16 demonstrates that both fracture (white solid arrows) and debonding (white dotted arrows) of hard inclusions occur on the fracture surface. It is interesting to notice that the fracture surface of the high-Fe specimen shows comparatively more iron-intermetallics. Fracture mainly occurs by fracture of the iron-intermetallics. Besides, the iron-intermetallics ( $\beta$-phase) that appear as long needle-like inclusions in 2D micrographs are seen as massive platelets in 3D (marked by dotted box in Figure 16(a) and (b)) as is confirmed by the X-ray elemental mapping in Figure 16(c) and (d). 

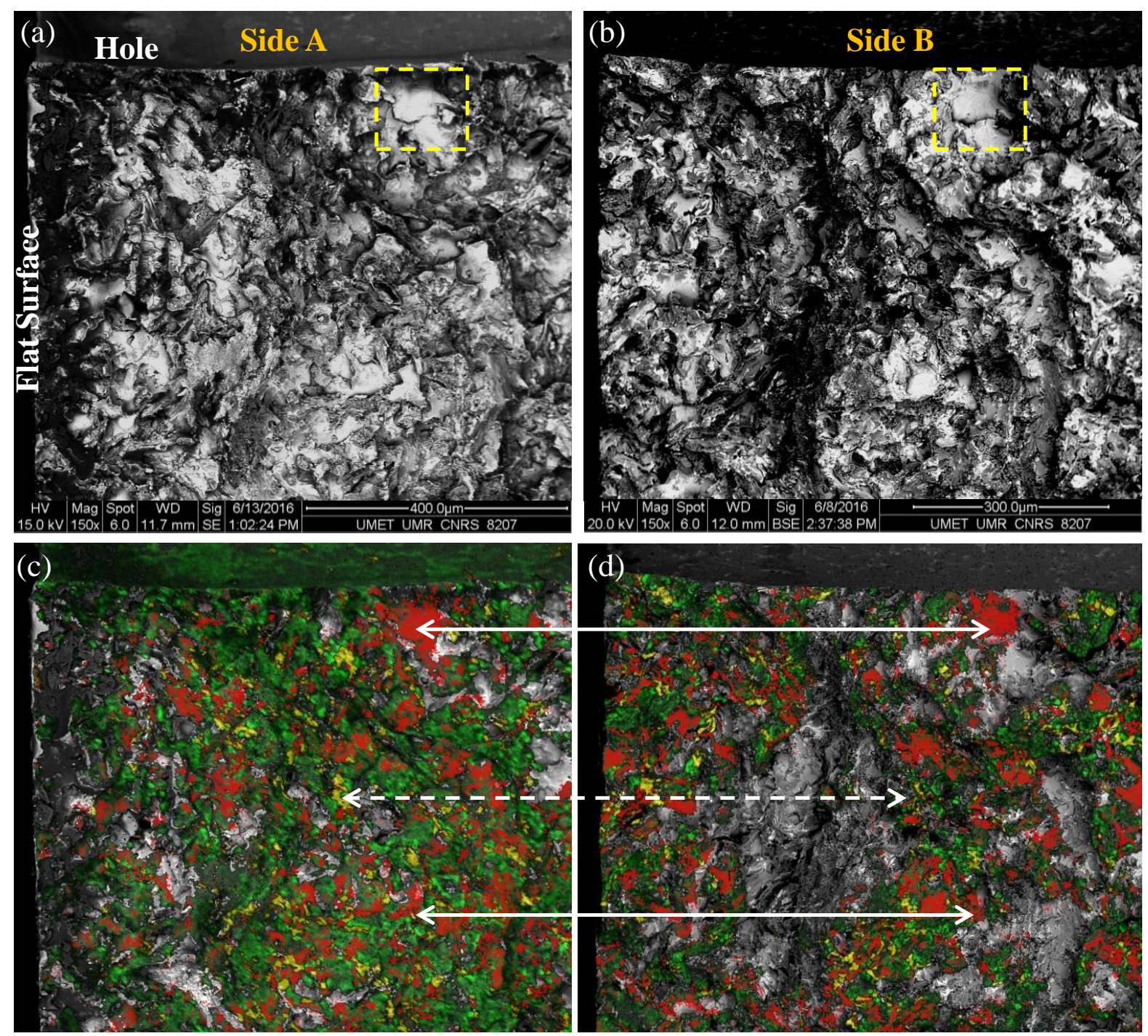

Fe-intermetallics

$\mathrm{Al}_{2} \mathrm{Cu}$

Eutectic Si

Figure $16:(a)$, (b) BSE images of the fracture surface of high-Fe specimen and (c), (d) corresponding $X$-ray mapping images showing the distribution of hard inclusions (eutectic Si, iron-intermetallics, $\mathrm{Al}_{2} \mathrm{Cu}$ phases).

\subsubsection{Quantitative analysis}

A quantitative chemical composition analysis has been performed on the fracture surface for the two specimens using SEM-EDX. It should be noted that there exists some areas that cannot be detected by EDX because of shadowing effects in the rough fracture surface.

The comparison of hard inclusions surface fraction between fracture surfaces and flat surfaces for both alloys is shown in Figure 17. It can be concluded that the fraction of hard inclusions is higher in the 
fracture surface than in the flat surface of specimen for both cases. That implies that cracks and final fracture are more prone to occur at $\mathrm{Si}$ phase, iron-intermetallics and $\mathrm{Al}_{2} \mathrm{Cu}$ phases than in $\mathrm{Al}$ dendrites.

(a)

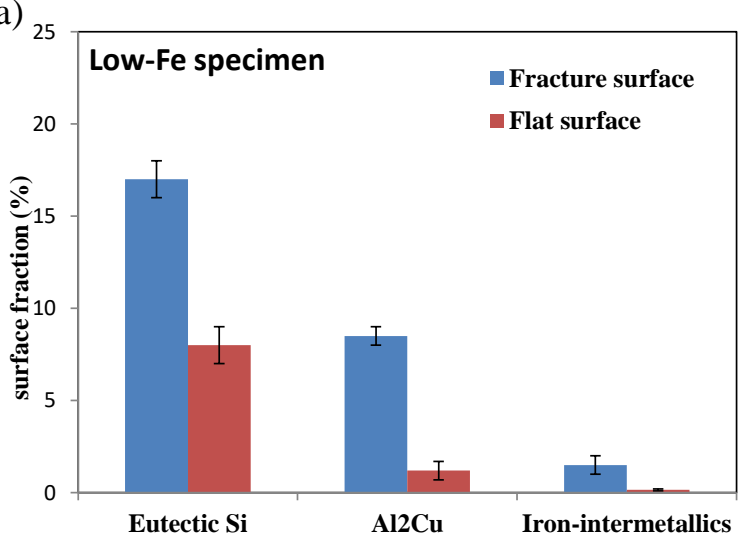

(b)

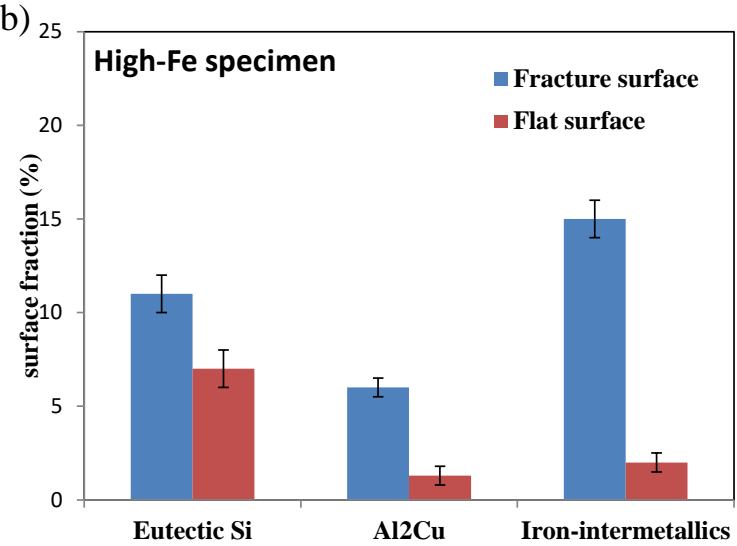

Figure 17: Surface fraction of hard inclusions in the fracture surface and in the material ("flat surface") for (a) low-Fe and (b) high-Fe specimen.

Although the fraction of $\mathrm{Al}_{2} \mathrm{Cu}$ phase (1.2-1.5\%) and eutectic Si (7-8\%) are similar in the flat surface of low-Fe and high-Fe specimen, more $\mathrm{Al}_{2} \mathrm{Cu}$ phase (8\% - 10\%) and eutectic $\mathrm{Si}(12 \%-16 \%)$ can be detected in the fracture surfaces of low-Fe alloy than in those of high-Fe alloy. The large fraction (14\% - 16\%) of iron-intermetallics, measured in the fracture surface of high-Fe alloy as compared to the 2D examination result of the flat surface (2-2.5\%), indicates that iron-intermetallics play a very important role whether in cracks initiation, cracks propagation or final fast fracture.

\section{Discussion}

In the present paper, the tensile damage mechanisms of two DC Al-Si-Cu alloys with different Fe level have been studied by field measurement and fracture analysis. The results show the iron-intermetallics inherited from Fe content play an important role on the tensile damage.

\subsection{Cracks initiation}

During the tensile tests, the large stress concentration around the hole [20] resulted in crack initiation at a gross stress between 184 and $195 \mathrm{MPa}$ for low-Fe specimen and between 133 and $150 \mathrm{MPa}$ for highFe specimen.

In low-Fe specimen, cracks have initiated from hard inclusions ( $\mathrm{Si}$ particles and $\mathrm{Al}_{2} \mathrm{Cu}$ phase) near the artificial hole or pore. Numerous studies have shown that pores have an important influence because they can generate enough strain localization for crack initiation [14] [21] [22]. In this work, the artificial hole can also introduce stress concentration as well as pores, resulting in crack initiation at hard inclusions around them. 
The fact that eutectic $\mathrm{Si}$ and $\mathrm{Al}_{2} \mathrm{Cu}$ phases act as the crack initiation sites have already been reported in Refs [21] [23]. This can be explained by the strain incompatibility between the aluminium matrix, which has an elasto-viscoplastic behaviour, and the hard inclusions (particularly Si particles). According to Seifeddine et al. [24] and Tabibian et al. [25], the hardness of hard inclusions obtained from nanoindentation measurements, i.e. iron-intermetallics (11.5-14.8 GPa), Si particles (13.3 GPa) and $\mathrm{Al}_{2} \mathrm{Cu}$ phase $(6.54 \mathrm{GPa})$, is larger than that of $\mathrm{Al}$ matrix (2.1 GPa) [24]. Thus the difference in hardness may explain the crack initiation on these hard particles.

In high-Fe specimen, cracks have initiated at iron-intermetallics rather than at eutectic $\mathrm{Si}$ and $\mathrm{Al}_{2} \mathrm{Cu}$ phases; the reason for this is mainly due to stress concentration enhancement and crack formation as a result of the presence of needle-like intermetallic compounds [26]. As was reported by Gao et al. [4], the most detrimental Fe-rich inclusions are the brittle needle-like $\beta$ - $\mathrm{Al}_{5} \mathrm{FeSi}$, which act as the main crack initiation sites in high-Fe Al-Si-Cu alloys. Moreover, sharp edges of the $\beta-\mathrm{Al}_{5} \mathrm{FeSi}$ introduce severe stress concentrations in the matrix, which contribute to the crack initiation.

\subsection{Cracks growth and final fracture}

Once cracks have initiated, they are prone to grow along hard inclusions including $\mathrm{Si}$ phase, $\mathrm{Al}_{2} \mathrm{Cu}$ phases and iron-intermetallics. Cracks growth along hard inclusions can be ascribed to strain localizations at hard inclusions (e.g. in Figure 9(d)). Strain localizations have been indeed observed in areas where cracks propagations have been observed in following loading (e.g. in Figure 9(f)). In addition, fracture surfaces have been also examined with SEM in order to find the features responsible for crack growth and final fracture.

In low-Fe specimen, as is shown in Figure 13 and Figure 14, it seems most likely that the fracture is triggered in a relatively stiff region with a high fraction of eutectic $\mathrm{Si}$ and $\mathrm{Al}_{2} \mathrm{Cu}$ phases located at the fracture surface of specimen. It indicates that crack growth is prone to occur along eutectic Si particles and $\mathrm{Al}_{2} \mathrm{Cu}$ phases. This may be due to the elastic modulus of both eutectic Si particles (185 GPa) [24] and $\mathrm{Al}_{2} \mathrm{Cu}$ phases (126 GPa) [25] that are higher than that of the aluminium matrix (typically $70 \mathrm{GPa}$ ); thus they are reported to play a role in crack propagation either as a barrier [27] or as a preferential path [28].

In high-Fe specimen, crack growth is observed to occur along hard inclusions, essentially ironintermetallics. As is shown in Figure 16, more iron intermetallics than eutectic Si or copper containing phases have been observed in crack growth path.

From the results, several reasons may be proposed:

1) The iron-intermetallics exhibit a high elastic modulus (166-180 GPa) in comparison with other eutectic/intermetallic phases [25], which may introduce incompatibility of deformation between 
the iron-intermetallics particles and the aluminium matrix, leading to damage by fracture or by debonding of iron-intermetallics particles [29] [30].

2) Both studied alloys are modified by $\mathrm{Sr}$ (Strontium). The microstructure characterization shows that eutectic $\mathrm{Si}$ particles in modified $\mathrm{Al}-\mathrm{Si}-\mathrm{Cu}$ alloys appear with fibrous morphology. Consequently, compared with these fibrous Si particles, the needle-like $\mathrm{Al}_{5} \mathrm{FeSi}$ intermetallics are more likely to generate stress concentration.

Besides, fracture and debonding of hard inclusions are observed in both specimens. However, the failure mechanism of the hard inclusions seems to be more fracture than decohesion during tensile test. The failure mode of hard inclusions within the aluminium matrix depends on the loading conditions and phase morphology [23, 31]. Fracture is likely to occur at large and irregularly shaped hard inclusions under a high crack tip driving force. In the present case, due to the high tensile stress, the hard inclusions, especially needle-like $\beta-\mathrm{Al}_{5} \mathrm{FeSi}$ phases, are prone to cracking rather than debonding at particle/matrix interface during the tensile loading. This result is in agreement with the observations by Ma [32], who reported that crack initiation and propagation occur through cleavage of $\beta-\mathrm{Al}_{5} \mathrm{FeSi}$ platelets rather than by decohesion of the $\beta$-platelets from the matrix.

\section{Conclusions and perspective}

The effects of Fe-content on damage mechanisms have been studied for two A319 alloys using in-situ tensile test together with DIC analysis. The following conclusions can be drawn:

1) In the low-Fe alloy ( 0.1 wt. \% Fe), crack initiation occurs through the fracture of Si particles and $\mathrm{Al}_{2} \mathrm{Cu}$ particles in the high stress concentration region around the artificial hole. The existence of pores also facilitates crack initiation. Crack growth is prone to occur along the eutectic $\mathrm{Si}$ and $\mathrm{Al}_{2} \mathrm{Cu}$ phases. Micro-cracks are detected in the $\mathrm{Al}_{2} \mathrm{Cu}$ phase which is close to the crack path in the SEM images. In addition, the fractography analysis highlights the role of hard inclusions on crack propagation, and reveals that crack propagation under monotonic load occurs through the eutectic $\mathrm{Si}, \mathrm{Al}_{2} \mathrm{Cu}$ phases and primary phases, exhibiting some fracture of the $\mathrm{Al}_{2} \mathrm{Cu}$ phases and eutectic Si particles.

2) In the high-Fe alloy ( 0.8 wt. \% Fe), cracks initiate at hard inclusions in areas with sufficient stress concentrations. Cracks appear more likely to occur through the fracture of ironintermetallics. Thereafter, crack growth occurs through the cleavage of iron-intermetallics. Cracks also propagate through the fracture of $\mathrm{Al}_{2} \mathrm{Cu}$, as well as through that of brittle Si particles.

This study of the influence of Fe content on damage mechanisms under monotonic loading is a preliminary and necessary work before studying the influence of microstructure on the fatigue properties of A319 alloy. Studies on the fatigue behaviour of such a material has already been undertaken in the 
laboratory [1, 14]using specimens cut out of cast cylinder heads but without any control over the composition of the alloy. Some interesting results have been obtained on the influence of pores on crack initiation at the first loading cycle, i.e. during monotonic loading [14]. However, the present study shows that a control of the composition is needed to yield a better understanding of the microstructure, i.e. hard inclusions, influence on the damage mechanisms first under monotonic loading and, in the near future, under cyclic loading.

\section{Acknowledgement}

The authors wish to thank the ANR (Agence Nationale de la Recherche) MatetPro project INDiANA (ANR-12RMNP-0011) for funding the study on Al-Si alloys, Pierre Osmond from PSA Peugeot Citroën for providing the material of this study and the China Scholarship Council (CSC) for funding the PhD thesis of Zaidao Li.

\section{References}

[1] Dahdah N, Limodin N, El Bartali A, Witz J, Seghir R, Charkaluk E, et al. Damage Investigation in A319 Aluminium Alloy by X - ray Tomography and Digital Volume Correlation during In Situ High Temperature Fatigue Tests. Strain. 2016;52:324-35.

[2] Bacaicoa I, Dwivedi PK, Luetje M, Zeismann F, Brueckner-Foit A, Geisert A, et al. Effect of nonequilibrium heat treatments on microstructure and tensile properties of an $\mathrm{Al}-\mathrm{Si}-\mathrm{Cu}$ alloy. Materials Science and Engineering: A. 2016;673:562-71.

[3] Hurtalová L, Tillová E, Chalupová M, Ďuriníková E. Effect of chemical composition of secondary Al-Si cast alloy on intermetallic phases. Mach Technol Mater. 2012;6:11-4.

[4] Yi JZ, Gao YX, Lee PD, Lindley TC. Effect of Fe-content on fatigue crack initiation and propagation in a cast aluminum-silicon alloy (A356-T6). Materials Science and Engineering: A. 2004;386:396-407.

[5] Yates JR, Zanganeh M, Tai YH. Quantifying crack tip displacement fields with DIC. Engineering Fracture Mechanics. 2010;77:2063-76.

[6] Sutton M, Mingqi C, Peters W, Chao Y, McNeill S. Application of an optimized digital correlation method to planar deformation analysis. Image and Vision Computing. 1986;4:143-50.

[7] Sutton MA, Orteu JJ, Schreier H. Image correlation for shape, motion and deformation measurements: basic concepts, theory and applications: Springer Science \& Business Media; 2009.

[8] Limodin N, El Bartali A, Wang L, Lachambre J, Buffiere J-Y, Charkaluk E. Application of X-ray microtomography to study the influence of the casting microstructure upon the tensile behaviour of an Al-Si alloy. Nuclear Instruments and Methods in Physics Research Section B: Beam Interactions with Materials and Atoms. 2014;324:57-62.

[9] Haddadi H, Belhabib S. Use of rigid-body motion for the investigation and estimation of the measurement errors related to digital image correlation technique. Optics and Lasers in Engineering. 2008;46:185-96. 
[10] Spagnoli A, Carpinteri A, Ferretti D, Vantadori S. An experimental investigation on the quasi brittle fracture of marble rocks. Fatigue \& Fracture of Engineering Materials \& Structures. 2016.

[11] Carpinteri A, Fernández-Canteli A, Fortese G, Muñiz-Calvente M, Ronchei C, Scorza D, et al. Probabilistic failure assessment of Fibreglass composites. Composite Structures. 2017;160:1163-70.

[12] Russ JC, Woods RP. The image processing handbook. Journal of Computer Assisted Tomography. 1995;19:979-81.

[13] Peterson RE, Plunkett R. Stress concentration factors. Journal of Applied Mechanics. 1975;42:248.

[14] Wang L, Limodin N, El Bartali A, Witz J-F, Seghir R, Buffiere J-Y, et al. Influence of pores on crack initiation in monotonic tensile and cyclic loadings in lost foam casting A319 alloy by using 3D in-situ analysis. Materials Science and Engineering: A. 2016.

[15] Zwieg T. Specimen preparation for high edge retention of aluminum alloys. Industrial heating. 2003;70:43-5.

[16] Thévenaz P, Unser M. User - friendly semiautomated assembly of accurate image mosaics in microscopy. Microscopy research and technique. 2007;70:135-46.

[17] Seghir R, Witz JF, Coudert S. YaDICs - Digital Image Correlation 2/3D software.

[18] Petzow G. Metallographic etching: techniques for metallography, ceramography, plastography: ASM international; 1999.

[19] Li Z, Limodin N, Tandjaoui A, Quaegebeur P, Osmond P, Balloy D. Influence of Sr, Fe and Mn content and casting process on the microstructures and mechanical properties of $\mathrm{AlSi} 7 \mathrm{Cu} 3$ alloy. Materials Science and Engineering: A. 2017;689:286-97.

[20] Pilkey WD, Pilkey DF. Peterson's stress concentration factors: John Wiley \& Sons; 2008.

[21] Dezecot S, Buffiere J-Y, Koster A, Maurel V, Szmytka F, Charkaluk E, et al. In situ 3D characterization of high temperature fatigue damage mechanisms in a cast aluminum alloy using synchrotron X-ray tomography. Scripta Materialia. 2016;113:254-8.

[22] Fan J, McDowell DL, Horstemeyer MF, Gall K. Cyclic plasticity at pores and inclusions in cast Al-Si alloys. Engineering Fracture Mechanics. 2003;70:1281-302.

[23] Horstemeyer MF. Integrated Computational Materials Engineering (ICME) for metals: using multiscale modeling to invigorate engineering design with science: John Wiley \& Sons; 2012.

[24] Seifeddine S, Johansson S, Svensson IL. The influence of cooling rate and manganese content on the $\beta$-Al5FeSi phase formation and mechanical properties of Al-Si-based alloys. Materials Science and Engineering: A. 2008;490:385-90.

[25] Tabibian S, Charkaluk E, Constantinescu A, Guillemot G, Szmytka F. Influence of process-induced microstructure on hardness of two Al-Si alloys. Materials Science and Engineering: A. 2015;646:190200.

[26] Ceschini L, Morri A, Morri A, Gamberini A, Messieri S. Correlation between ultimate tensile strength and solidification microstructure for the sand cast A357 aluminium alloy. Materials \& Design. 2009;30:4525-31. 
[27] Zeng L, Sakamoto J, Fujii A, Noguchi H. Role of eutectic silicon particles in fatigue crack initiation and propagation and fatigue strength characteristics of cast aluminum alloy A356. Engineering Fracture Mechanics. 2014;115:1-12.

[28] Chan KS, Jones P, Wang Q. Fatigue crack growth and fracture paths in sand cast B319 and A356 aluminum alloys. Materials Science and Engineering: A. 2003;341:18-34.

[29] Buffière JY, Savelli S, Jouneau PH, Maire E, Fougères R. Experimental study of porosity and its relation to fatigue mechanisms of model $\mathrm{Al}-\mathrm{Si} 7-\mathrm{Mg} 0.3$ cast $\mathrm{Al}$ alloys. Materials Science and Engineering: A. 2001;316:115-26.

[30] Dezecot S, Brochu M. Microstructural characterization and high cycle fatigue behavior of investment cast A357 aluminum alloy. International Journal of Fatigue. 2015;77:154-9.

[31] Gall K, Yang N, Horstemeyer M, McDowell DL, Fan J. The debonding and fracture of Si particles during the fatigue of a cast Al-Si alloy. Metallurgical and Materials Transactions A. 1999;30:3079-88.

[32] Ma Z, Samuel A, Doty H, Valtierra S, Samuel F. Effect of Fe content on the fracture behaviour of Al-Si-Cu cast alloys. Materials \& Design. 2014;57:366-73. 